\title{
Modeling and optimization of Electrical Discharge Machining (EDM) using statistical design
}

\author{
Husein A. Hegab ${ }^{1}$, Mohamed H. Gadallah ${ }^{1, *}$, and Amal K. Esawi ${ }^{2}$ \\ 1 Department of Mechanical Design and Production Engineering, Cairo University, 12613 Giza, Egypt \\ 2 Department of Mechanical Engineering, The American University in Cairo, 11835 Cairo, Egypt
}

Received 21 August 2015 / Accepted 22 September 2015

\begin{abstract}
Modeling and optimization of nontraditional machining is still an ongoing area of research. The objective of this work is to optimize Electrical Discharge Machining process parameters of Aluminum-multiwall carbon Nanotube composites (AL-CNT) model. Material Removal Rate (MRR), Wear Electrode Ratio (EWR) and Average Surface Roughness $(R a)$ are primary objectives. The Machining parameters are machining-on time (sec), discharge current (A), voltage (V), total depth of cut (mm), and \%wt. CNT added. Mathematical models for all responses as function of significant process parameters are developed using Response Surface Methodology (RSM). Experimental results show optimum levels for material removal rate are \%wt. CNT $(0 \%)$, high level of discharge current $(6 \mathrm{~A})$ and low level of voltage $(50 \mathrm{~V})$ while optimum levels for Electrode wear ratio are \%wt. CNT (5\%), high level of discharge current (6A) and optimum levels for average surface roughness are \%wt. CNT (0\%), low level of discharge current (2A) and high level of depth of cut $(1 \mathrm{~mm})$. Single-objective optimization is formulated and solved via Genetic Algorithm. Multi-objective optimization model is then formulated for the three responses of interest. This methodology gathers experimental results, builds mathematical models in the domain of interest and optimizes the process models. As such, process analysis, modeling, design and optimization are achieved.
\end{abstract}

Key words: Taguchi approach, Response Surface Methodology (RSM), AL-CNT composites, Electrical Discharge Machining (EDM), Modeling and optimization

\section{Introduction}

Electrical Discharge Machine (EDM) is a widespread technique used for high precision machining of metals, metallic alloys, graphite, and some ceramic materials of high hardness. EDM technology is used in tool, die and mold making industries, heat treated tool steels and advanced materials (super alloys, ceramics, and metal matrix composites) require high precision, complex shapes and high surface finish. It is based on the eroding effect of an electric spark on both electrodes used. It utilizes the removal phenomenon of electricaldischarge in dielectric. Therefore, the electrode affects the material removal rate and the tool wear rate [1].

Some researchers studied EDM of composite materials and ceramics [2]. Developing mathematical models for optimizing EDM characteristics such as material removal rate, wear electrode ratio and surface roughness are objectives. Experimentation and mathematical models with linear, quadratic and interactive effects of some parameters chosen are developed

*e-mail: mohamed@aucegypt.edu using three level full factorial design [3]. Gopalakannan et al. prepared Metal Matrix Composites (MMCs) of Aluminum 7075 with $10 \%$ wt. of $\mathrm{B}_{4} \mathrm{C}$ particles by stair casting method. ANOVA is applied to investigate the influence of process parameters and their interactions on material removal rate (MRR) and electrode wear rate (EWR), and surface roughness (SR) respectively [4].

Habib studied responses like material removal rate, electrode wear ratio, gap size and surface roughness through experimentation. $\mathrm{Al} / \mathrm{Sic}$ composite material is used and correlations between the cutting rates are shown. Optimal combination of these parameters is obtained to achieve controlled EDM [5]. Mohan Pradhan and Chandan Biswas used Response Surface Methodology to investigate the relationships and parametric interactions between the three controllable variables on the material removal rate (MRR). Experiments are conducted on AISI D2 tool steel with copper electrode and three process variables (factors) as discharge current, pulse duration, and pulse off time respectively [6].

This paper develops mathematical models of various machining parameters, such as machining-on time (sec), 
discharge current (A), voltage (V), total depth of cut (mm), and $\%$ wt. CNT present in the aluminum matrix on the material removal rate, wear electrode ratio and average surface roughness respectively. Machining parameters optimization are carried out through Taguchi optimization methodology. Mathematical models are developed through Response Surface Methodology (RSM). Single and multi-objective optimization models are formulated and solved via developed optimization toolbox in MATLAB environment.

\section{Material and methods}

EDM operations are conducted by CHEMR 50 MP Ram EDM machine with the provision of programming in the $Z$-vertical axis-control and manually operating $X$ and $Y$ axes. Experiments are carried out on Aluminum-multiwall carbon Nanotube composites (Al-CNT). A 99.7\% pure AlPOCO ${ }^{\circledR}$ aluminum powder having an average particle size of $75 \mu$, in addition to $70-90 \%$ pure Elicarb ${ }^{\circledR}$ multi-walled carbon nanotubes having 10-12 $\mathrm{nm}$ average diameter are utilized in the synthesis of multiwall carbon nanotube reinforced aluminum composites. Al-CNT powder mixture is milled for $1 \mathrm{hr}$ using high energy ball milling at $400 \mathrm{rpm}$, milled powder then double hot compacted at $500{ }^{\circ} \mathrm{C}$ and $100 \mathrm{bar}$. The specimen shape is in form of cuboids with length $45 \mathrm{~mm}$, width $43.2 \mathrm{~mm}$ and thickness $12 \mathrm{~mm}$. The experiments are performed using copper electrodes with rectangular cross section area of $15 \mathrm{~mm}$ length and $4 \mathrm{~mm}$ width. Commercial kerosene is used as a dielectric fluid. Material removal rate is calculated by measuring the loss in workpiece weight after machining. Wear electrode ratio is calculated by ratio between loss in weight of workpiece and loss in weight of electrode. Material removal rate (MRR) in $\mathrm{gm} / \mathrm{min}$ and electrode wear ratio (EWR) are calculated by the following formulae:

$$
\begin{gathered}
\mathrm{MRR}=\Delta \mathrm{W} / T_{\mathrm{m}}, \\
\mathrm{EWR}=\Delta \mathrm{W}_{\text {electrode }} / \Delta \mathrm{W}_{\text {specimen }},
\end{gathered}
$$

where $T_{\mathrm{m}}$ is machining time in minutes, $\Delta \mathrm{W}_{\text {specimen }}$ is the workpiece weight loss in gm, and $\Delta \mathrm{W}_{\text {electrode }}$ is the electrode weight loss in gm.

The average surface roughness parameter $(R a)$ is used to quantify the surface roughness of the machined surface. $R a$ is measured using a contact type stylus based on surface roughness tester. The device employed is Surtronic 3P and manufactured by Rank Taylor Hobson (Denmark). Surface roughness is measured on the EDM machined area three times and the average value is used. Cut-off length used is $2.5 \mathrm{~mm}$ and the unit of measure is $\mu \mathrm{m}$.

\section{Theory of experimental design}

An L27 orthogonal array based on the Taguchi method is employed for experiments. $\mathrm{L}_{27}\left(3^{13}\right)$ has 27 rows corresponding to the number of tests (26 degrees of freedom) with 13 columns at three levels. The plan of experiment is made

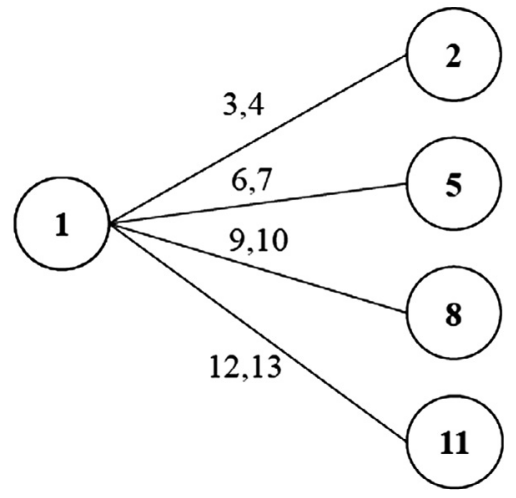

Figure 1. Search graph for L27OA [7].

of 27 tests in which the first column is assigned to percentage of CNT added (wt.\% CNT), the second column to discharge current (A), the fifth column to voltage $(\mathrm{V})$, the eighth column to machining on time (sec), eleventh column to depth of cut $(\mathrm{mm})$ and the remaining are assigned to the interactions as shown in Figure 1. Tests are replicated, resulting in a total of 81 tests, to allow the analysis of variance and signal to noise ratio calculation. Five factors are used at three levels. Table 1 indicates the factors studied and the assignment of the corresponding levels. The full factorial array is L243 $\left(3^{5}\right)$; however fractional factorial array L27OA is used in this study.

$S / N$ ratios are calculated from the measured values. In this study, the experimentally observed MRR value is "the higher the better" (HB), the EWR value is "the lower the better" (LB), and the $R a$ value is "the lower the better" (LB). Analysis of variance results obtained from the $S / N$ ratios, mean, and standard deviation values are calculated. The related equations are as follows:

$$
\begin{gathered}
\mathrm{HB}: S / N=-\log (1 / n)\left(\Sigma y^{2}\right), \\
\mathrm{LB}: S / N=-\log (1 / n)\left(\sum 1 / y^{2}\right),
\end{gathered}
$$

where $n$ is the number of observations, and $y$ is the observed data. For each transformation, the higher the $S / N$ ratio the better. Table 1 gives the control parameters and corresponding values.

\section{Results and discussions}

\subsection{Analysis of experimental results}

The plan of tests is developed with aim of relating the influence of control variables to all measured responses. The effects of factors and their interactions through analysis of the experimental results, determine the optimum levels and verification of experiments results based on signal to noise ratio, ANOVA and analysis of means (ANOM). Results of Material removal rate, wear electrode ratio and average surface roughness responses (three replicated values) are shown in Table 2. 
Table 1. Assignment of levels to control factors.

\begin{tabular}{|c|c|c|c|c|}
\hline & & Level 1 & Level 2 & Level 3 \\
\hline & \%CNT added (\%wt.) & $0 \%$ & $2.5 \%$ & $5 \%$ \\
\hline \multirow[t]{3}{*}{ Control factors } & Machining on time (sec) & 3 & 4 & 5 \\
\hline & Voltage (V) & 50 & 60 & 70 \\
\hline & Total depth of cut (mm) & 0.5 & 0.75 & 1 \\
\hline
\end{tabular}

Table 2. Experimental results of material removal rate, wear electrode ratio and average surface roughness.

\begin{tabular}{|c|c|c|c|c|c|c|c|c|c|}
\hline \multirow[t]{2}{*}{ Run no. } & \multicolumn{3}{|c|}{$\begin{array}{l}\text { Material removal rate }(\mathrm{gm} / \mathrm{min}) \\
\text { (higher the better) }\end{array}$} & \multicolumn{3}{|c|}{$\begin{array}{l}\text { Wear electrode ratio } \\
\text { (lower the better) }\end{array}$} & \multicolumn{3}{|c|}{$\begin{array}{c}\text { Average surface roughness }(\mu \mathrm{m}) \\
\text { (lower the better) }\end{array}$} \\
\hline & 1st trial & 2nd trial & 3rd trial & 1st trial & 2nd trial & 3rd trial & 1st trial & 2nd trial & 3rd trial \\
\hline 1 & 0.0125 & 0.0156 & 0.0163 & 2.33 & 4.00 & 4.5 & 1.60 & 1.13 & 0.97 \\
\hline 2 & 0.0145 & 0.0151 & 0.0171 & 1.20 & 1.40 & 3.2 & 3.23 & 3.39 & 3.35 \\
\hline 3 & 0.0111 & 0.0129 & 0.012 & 3.00 & 2.00 & 1.4 & 3.40 & 1.10 & 1.10 \\
\hline 4 & 0.0154 & 0.014 & 0.0162 & 2.50 & 1.40 & 2.00 & 5.53 & 4.51 & 3.60 \\
\hline 5 & 0.016 & 0.0134 & 0.0122 & 4.000 & 2.33 & 3.00 & 3.40 & 3.35 & 3.63 \\
\hline 7 & 0.0362 & 0.035 & 0.0405 & 1.30 & 3.20 & 2.50 & 4.47 & 4.43 & 4.48 \\
\hline 8 & 0.0216 & 0.0237 & 0.0195 & 3.00 & 3.80 & 3.20 & 3.71 & 3.46 & 3.40 \\
\hline 9 & 0.0174 & 0.0132 & 0.0196 & 3.00 & 1.75 & 2.50 & 4.30 & 4.39 & 4.43 \\
\hline 10 & 0.008 & 0.0071 & 0.0076 & 3.10 & 2.50 & 2.00 & 6.07 & 7.76 & 8.31 \\
\hline 11 & 0.0028 & 0.0026 & 0.0032 & 1.28 & 2.00 & 3.33 & 6.18 & 6.73 & 5.45 \\
\hline 12 & 0.0068 & 0.0056 & 0.0071 & 1.88 & 2.50 & 2.57 & 4.34 & 3.78 & 4.03 \\
\hline 17 & 0.0041 & 0.0050 & 0.0043 & 0.68 & 1.31 & 1.20 & 5.02 & 4.81 & 4.86 \\
\hline 18 & 0.018 & 0.0131 & 0.012 & 1.50 & 1.60 & 1.16 & 8.66 & 9.57 & 9.46 \\
\hline 19 & 0.0072 & 0.0062 & 0.0086 & 1.14 & 0.87 & 1.50 & 7.05 & 5.38 & 6.74 \\
\hline 20 & 0.003 & 0.0031 & 0.0031 & 1.22 & 1.22 & 1.22 & 5.38 & 3.98 & 4.40 \\
\hline 21 & 0.0046 & 0.0041 & 0.005 & 1.40 & 1.44 & 2.66 & 2.81 & 2.88 & 1.58 \\
\hline 22 & 0.0108 & 0.0095 & 0.0123 & 0.81 & 1.00 & 1.30 & 5.10 & 4.89 & 5.16 \\
\hline 23 & 0.0043 & 0.005 & 0.004 & 1.20 & 1.75 & 0.83 & 9.00 & 9.68 & 9.68 \\
\hline 24 & 0.0068 & 0.0077 & 0.0074 & 0.91 & 1.20 & 1.08 & 4.59 & 5.62 & 5.47 \\
\hline 25 & 0.024 & 0.0177 & 0.0311 & 0.85 & 0.84 & 1.40 & 6.54 & 6.54 & 6.65 \\
\hline 26 & 0.0392 & 0.0366 & 0.0342 & 1.40 & 1.10 & 1.19 & 5.18 & 5.57 & 5.75 \\
\hline 27 & 0.0127 & 0.0085 & 0.0111 & 0.87 & 0.85 & 1.40 & 8.50 & 8.45 & 8.40 \\
\hline
\end{tabular}

\subsubsection{Material removal rate}

Table 3 gives ANOVA results for material removal rate based on $S / N$ ratios; while Table 4 gives ANOM results and finally Table 5 gives ANOVA results based on standard deviations. Using material removal rate and $S / N$ ratio transformation, \%wt. CNT, discharge current and voltage are significant factors in affecting $S / N$ ratio at $90 \%$ confidence level. All interactions effects: $\mathrm{X}_{1} \cdot \mathrm{X}_{2}, \mathrm{X}_{1} \cdot \mathrm{X}_{3}, \mathrm{X}_{1} \cdot \mathrm{X}_{4}$, and $\mathrm{X}_{1} \cdot \mathrm{X}_{5}$ are not significant at any confidence level. Both \%wt. CNT and discharge current are significant at $95 \%$ and $99 \%$ confidence levels respectively. Using material removal rate as response based on mean values indicates that \%wt. CNT and discharge current are statistically significant at all confidence levels. All interaction effects are statistically insignificant at all confidence levels. It is observed that several parameters are insignificant, although they contribute a good percentage to the total statistical sum of squares. For instance, $\mathrm{X}_{1} \cdot \mathrm{X}_{5}$ has a contribution of $9.5 \%$ and voltage $\left(\mathrm{X}_{3}\right)$ has a contribution of $7.5 \%$ respectively. This means that all parameters should be include in the resulting mathematical model. Using material removal rate, \%wt. CNT and discharge current are statistically significant at all confidence levels respectively. Voltage $\left(\mathrm{X}_{3}\right)$ has a contribution of $7.6 \%$, yet statistically insignificant at any confidence level. All interaction terms are insignificant at all confidence levels.

\subsubsection{Electrode wear ratio}

Using electrode wear ratio and $S / N$ ratio transformation, $\%$ wt. CNT, discharge current are significant at all confidence levels respectively as shown in Table 6. Similarly, all interaction effects are insignificant at any confidence level. Using electrode wear ratio, only \%wt. CNT is statistically significant at any confidence level. Again, both discharge current and $\mathrm{X} 1 \cdot \mathrm{X} 2$ interaction effect have a contribution of $11.5 \%$, yet 
Table 3. ANOVA results for material removal rate based on $S / N$ ratios.

\begin{tabular}{|c|c|c|c|c|c|c|c|}
\hline \multicolumn{3}{|c|}{$S / N$ by factor level $(\mathrm{dB})$} & $\begin{array}{c}\text { Degree of } \\
\text { freedom (DoF) }\end{array}$ & $\begin{array}{c}\text { Sum of square } \\
\text { (SS) }\end{array}$ & $\begin{array}{c}\text { Mean square } \\
\text { (V) }\end{array}$ & $\begin{array}{l}\text { Value of } \\
F_{\text {calculated }}\end{array}$ & $\begin{array}{c}\text { Contribution } \\
\text { percentage } \mathrm{P} \%\end{array}$ \\
\hline \multicolumn{8}{|c|}{$\mathrm{X}_{1}: \%$ wt. CNT } \\
\hline \multicolumn{8}{|c|}{$\mathrm{X}_{2}$ : Discharge current } \\
\hline 388.18 & 362.41 & 316.90 & 2 & 289.54 & 144.77 & 8.02 & 29.6 \\
\hline \multicolumn{8}{|c|}{$\mathrm{X}_{4}$ : Machining on time [pooled factor] } \\
\hline 347.35 & 364.01 & 356.13 & 2 & 15.42 & 7.71 & - & - \\
\hline \multicolumn{8}{|c|}{$\mathrm{X}_{5}:$ Depth of cut [pooled factor] } \\
\hline 366.76 & 348.38 & 352.35 & 2 & 20.78 & 10.39 & - & - \\
\hline \multicolumn{8}{|c|}{$\mathrm{X}_{1} \cdot \mathrm{X}_{2}:$ Interaction factor [pooled factor] } \\
\hline \multicolumn{8}{|c|}{$\mathrm{X}_{1} \cdot \mathrm{X}_{3}$ : Interaction factor [pooled factor] } \\
\hline \multicolumn{8}{|c|}{$\mathrm{X}_{1} \cdot \mathrm{X}_{4}$ : Interaction factor } \\
\hline 356.59 & 365.9 & 344.96 & 4 & 24.53 & 6.13 & 0.34 & 2.5 \\
\hline \multicolumn{8}{|c|}{$\mathrm{X}_{1} \cdot \mathrm{X}_{5}:$ Interaction factor } \\
\hline 364.89 & 339.4 & 363.19 & 4 & 45.1 & 11.27 & 0.62 & 4.6 \\
\hline Error & & & 12 & 216.54 & 18.04 & & 22 \\
\hline Total & & & 26 & 979.62 & & & 100 \\
\hline
\end{tabular}

Table 4. ANOM results for material removal.

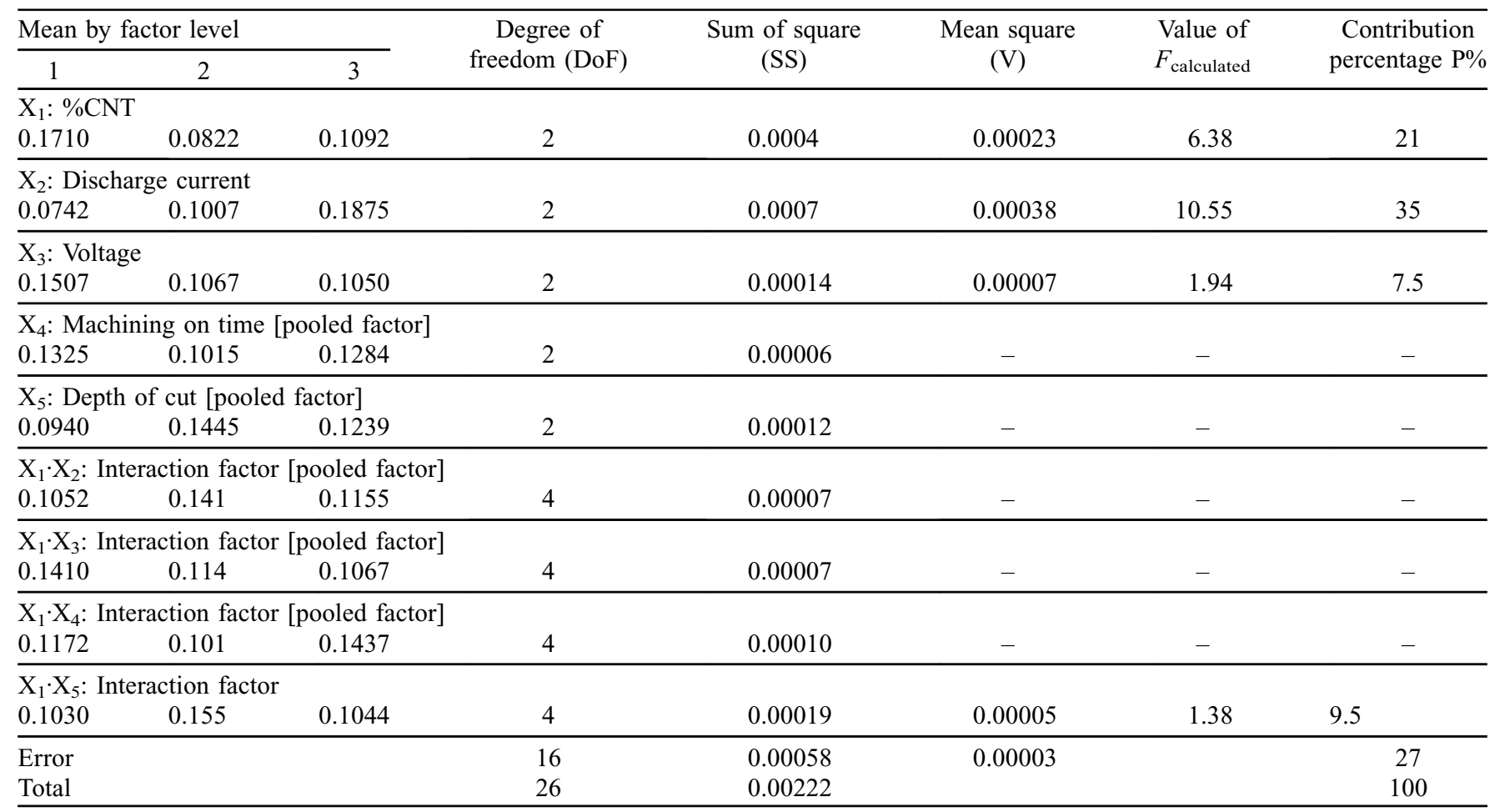

statistically insignificant at any confidence level as shown in Table 7. Using wear electrode ratio, \%wt. CNT and discharge current are statistically significant at $95 \%$ confidence level.
Only \%wt. CNT is statistically significant at $99 \%$ confidence level. None of the interactions are significant at any confidence level as shown in Table 8. 
Table 5. ANOVA results for material removal.

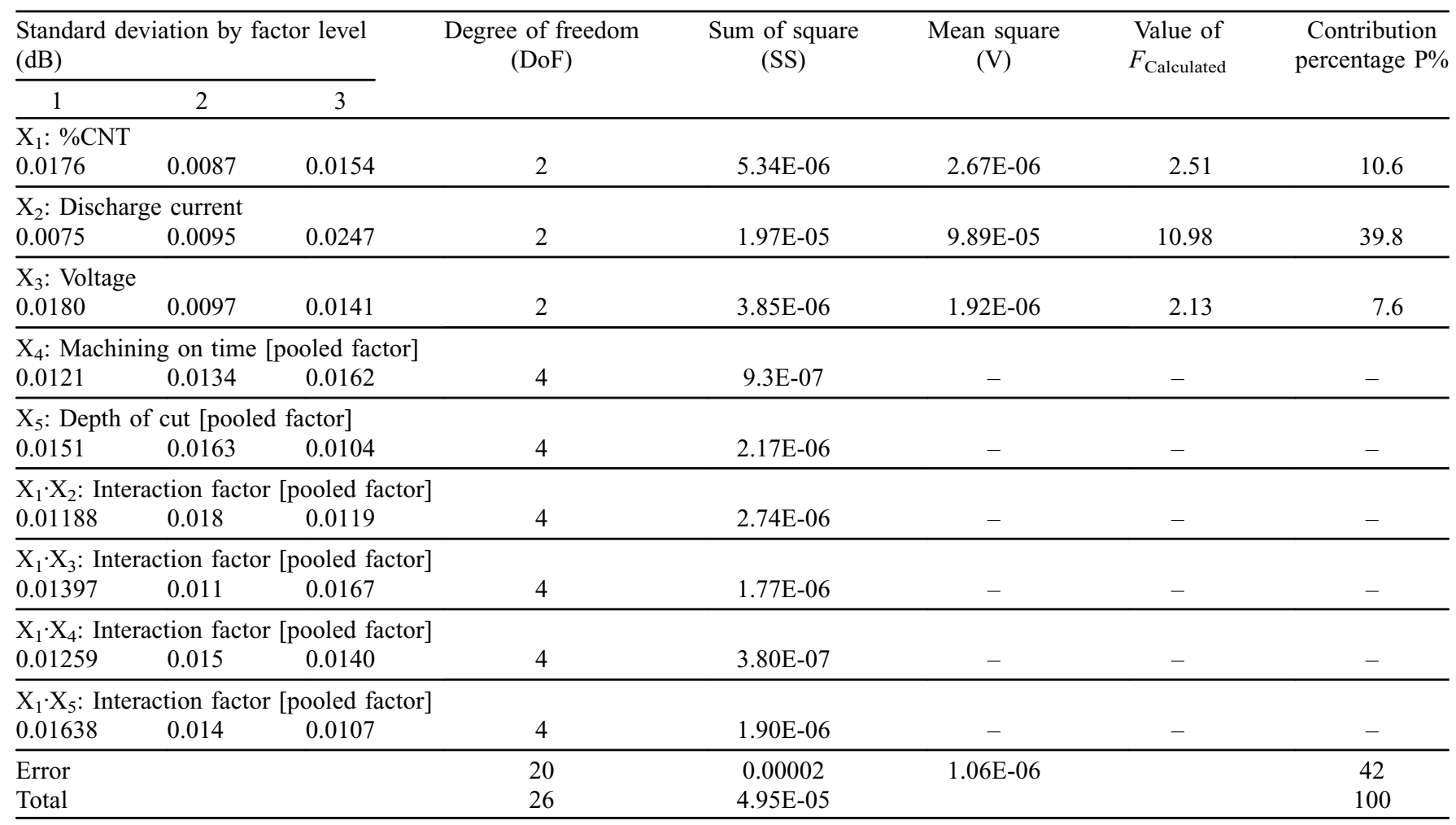

Table 6. ANOVA results for electrode wear ratio based on $S / N$ ratios.

\begin{tabular}{|c|c|c|c|c|c|c|c|}
\hline \multicolumn{3}{|c|}{$S / N$ by factor level $(\mathrm{dB})$} & \multirow{2}{*}{$\begin{array}{l}\text { Degree of freedom } \\
\text { (DoF) }\end{array}$} & \multirow{2}{*}{$\begin{array}{l}\text { Sum of square } \\
\text { (SS) }\end{array}$} & \multirow{2}{*}{$\begin{array}{c}\text { Mean square } \\
\text { (V) }\end{array}$} & \multirow{2}{*}{$\begin{array}{l}\text { Value of } \\
F_{\text {calculated }}\end{array}$} & \multirow{2}{*}{$\begin{array}{c}\text { Contribution } \\
\text { percentage } \mathrm{P} \%\end{array}$} \\
\hline 1 & 2 & 3 & & & & & \\
\hline \multicolumn{8}{|c|}{$\mathrm{X}_{1}: \%$ wt. CNT } \\
\hline 77.29 & 37.03 & 15.30 & 2 & 219.86 & 109.90 & 27.82 & 63.9 \\
\hline \multicolumn{8}{|c|}{$\mathrm{X}_{2}$ : Discharge current } \\
\hline 57.08 & 38.79 & 33.76 & 2 & 33.45 & 16.72 & 8.46 & 9.8 \\
\hline \multicolumn{8}{|c|}{$\mathrm{X}_{3}:$ Voltage [pooled factor] } \\
\hline \multicolumn{8}{|c|}{$\mathrm{X}_{4}$ : Machining on time [pooled factor] } \\
\hline 47.80 & 39.07 & 42.76 & 2 & 4.26 & - & - & - \\
\hline \multicolumn{8}{|c|}{$\mathrm{X}_{5}$ : Depth of cut [pooled factor] } \\
\hline 46.28 & 38.68 & 44.66 & 2 & 3.550 & - & - & - \\
\hline \multicolumn{8}{|c|}{$\mathrm{X}_{1} \cdot \mathrm{X}_{2}:$ Interaction factor } \\
\hline \multicolumn{8}{|c|}{$\mathrm{X}_{1} \cdot \mathrm{X}_{4}:$ Interaction factor [pooled factor] } \\
\hline 43.99 & 41.24 & 44.39 & 4 & 0.65 & - & - & - \\
\hline \multicolumn{8}{|c|}{$\mathrm{X}_{1} \cdot \mathrm{X}_{5}:$ Interaction factor [pooled factor] } \\
\hline 42.16 & 44.52 & 39.56 & 4 & 2.27 & - & - & - \\
\hline$\overline{\text { Error }}$ & & & 18 & 71.17 & 3.950 & & 20.6 \\
\hline Total & & & 26 & 344.32 & & & 100 \\
\hline
\end{tabular}

\subsubsection{Average surface roughness}

Using average surface roughness and $S / N$ ratio transformation, \%wt. CNT, discharge current and depth of cut are significant at all confidence levels respectively as shown in Table 9. Similarly, all interaction effects are insignificant at any confidence level. Using average surface roughness based on mean values, \%wt. CNT, discharge current and 
Table 7. ANOM results for electrode wear ratio.

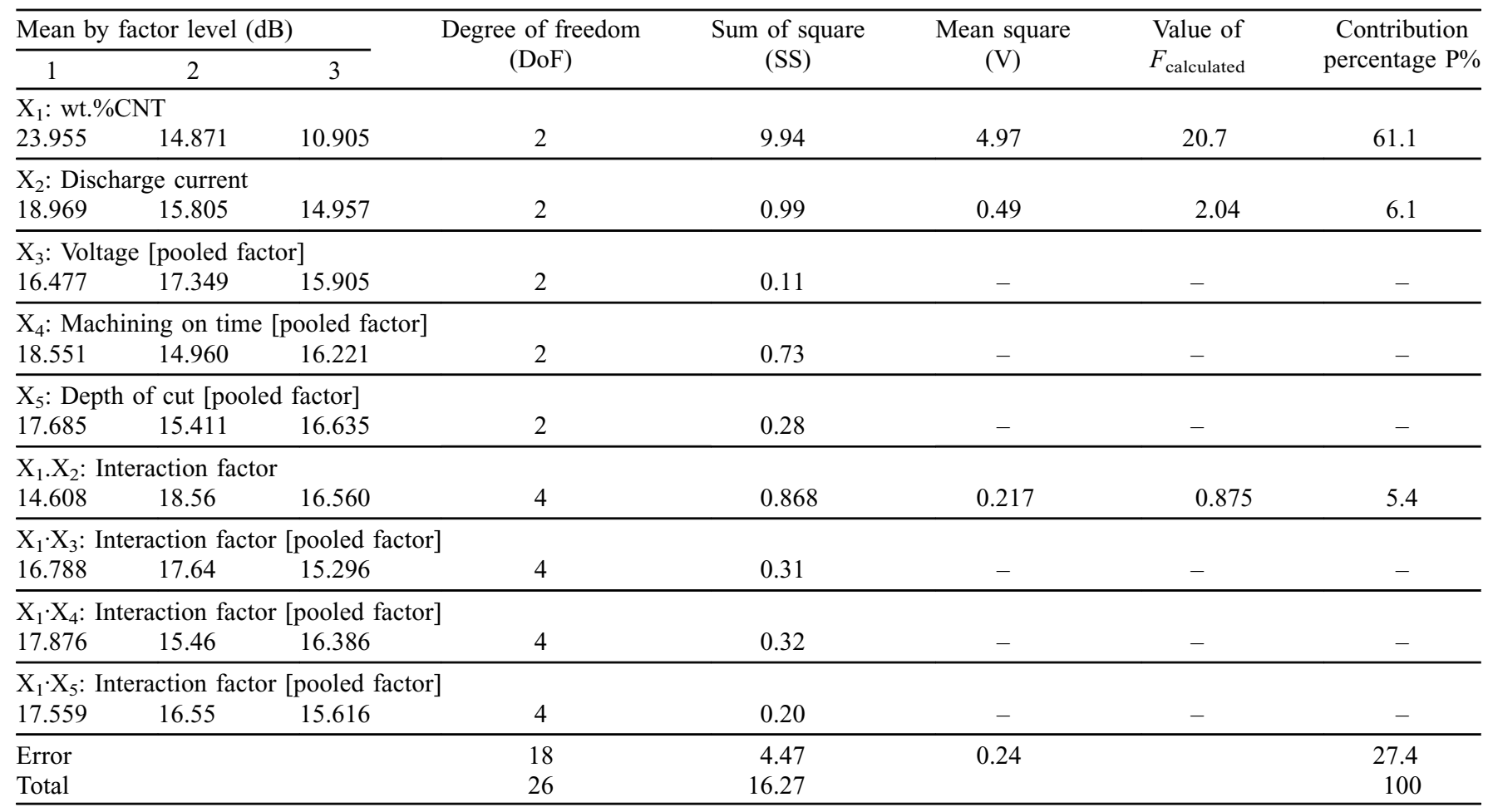

Table 8. ANOVA results for material removal.

\begin{tabular}{|c|c|c|c|c|c|c|c|}
\hline \multicolumn{3}{|c|}{$\begin{array}{l}\text { Standard deviation by factor level } \\
\text { (dB) }\end{array}$} & \multirow[t]{2}{*}{$\begin{array}{l}\text { Degree of freedom } \\
\text { (DoF) }\end{array}$} & \multirow[t]{2}{*}{$\begin{array}{c}\text { Sum of square } \\
\text { (SS) }\end{array}$} & \multirow[t]{2}{*}{$\begin{array}{c}\text { Mean square } \\
\text { (V) }\end{array}$} & \multirow[t]{2}{*}{$\begin{array}{l}\text { Value of } \\
F_{\text {calculated }}\end{array}$} & \multirow[t]{2}{*}{$\begin{array}{c}\text { Contribution } \\
\text { percentage } \mathrm{P} \%\end{array}$} \\
\hline 1 & 2 & 3 & & & & & \\
\hline \multicolumn{8}{|c|}{$\mathrm{X}_{1}: \%$ wt. CNT } \\
\hline \multicolumn{8}{|c|}{$\mathrm{X}_{2}$ : Discharge current } \\
\hline 6.0418 & 3.8050 & 3.6357 & 2 & 0.4 & 0.2 & 4.25 & 15.5 \\
\hline \multicolumn{8}{|c|}{$\mathrm{X}_{3}:$ Voltage [pooled factor] } \\
\hline \multicolumn{8}{|c|}{$\mathrm{X}_{4}$ : Machining on time [pooled factor] } \\
\hline 3.7455 & 4.7853 & 4.9517 & 2 & 0.09 & - & - & - \\
\hline \multicolumn{8}{|c|}{$\mathrm{X}_{5}:$ Depth of cut [pooled factor] } \\
\hline 4.6439 & 4.5539 & 4.2847 & 2 & 0.007 & - & - & - \\
\hline \multicolumn{8}{|c|}{$\mathrm{X}_{1} \cdot \mathrm{X}_{4}$ : Interaction factor [pooled factor] } \\
\hline 3.5357 & 4.779 & 5.1675 & 4 & 0.16 & - & - & - \\
\hline \multicolumn{8}{|c|}{$\mathrm{X}_{1} \cdot \mathrm{X}_{5}$ : Interaction factor [pooled factor] } \\
\hline 4.4524 & 4.722 & 4.3073 & 4 & 0.0098 & - & - & - \\
\hline Error & & & 22 & 1.044 & 0.047 & & 39.8 \\
\hline Total & & & 26 & 2.67 & & & 100 \\
\hline
\end{tabular}

depth of cut are statistically significant at any confidence level as shown in Table 10 . The interaction effect $\mathrm{X}_{1} \cdot \mathrm{X}_{5}$ is statistically significant at $95 \%$ confidence level. Using average surface roughness based on standard deviations, only discharge current is statistically significant at $95 \%$ confidence level as shown in Table 11. All other variables and interaction effects are statistically insignificant at any confidence level. 
Table 9. ANOVA results for average surface roughness based on $S / N$ ratios.

\begin{tabular}{|c|c|c|c|c|c|c|c|}
\hline \multicolumn{3}{|c|}{$S / N$ by factor level $(\mathrm{dB})$} & \multirow{2}{*}{$\begin{array}{l}\text { Degree of freedom } \\
\text { (DoF) }\end{array}$} & \multirow{2}{*}{$\begin{array}{l}\text { Sum of square } \\
\text { (SS) }\end{array}$} & \multirow{2}{*}{$\begin{array}{c}\text { Mean square } \\
\text { (V) }\end{array}$} & \multirow{2}{*}{$\begin{array}{l}\text { Value of } \\
F_{\text {calculated }}\end{array}$} & \multirow{2}{*}{$\begin{array}{c}\text { Contribution } \\
\text { percentage } \mathrm{P} \%\end{array}$} \\
\hline 1 & 2 & 3 & & & & & \\
\hline \multicolumn{8}{|c|}{$\overline{\mathrm{X}_{1}: \% w t . \mathrm{CNT}}$} \\
\hline 92.01 & 138.53 & 135.1 & 2 & 149.32 & 74.66 & 13.45 & 35.7 \\
\hline \multicolumn{8}{|c|}{$\mathrm{X}_{2}$ : Discharge current } \\
\hline 101.96 & 125.46 & 138.22 & 2 & 75.17 & 37.58 & 6.77 & 18 \\
\hline \multicolumn{8}{|c|}{$\mathrm{X}_{3}:$ Voltage [pooled factor] } \\
\hline \multicolumn{8}{|c|}{$\mathrm{X}_{4}$ : Machining on time [pooled factor] } \\
\hline 117.45 & 127.62 & 120.49 & 2 & 6.03 & - & - & - \\
\hline \multicolumn{8}{|c|}{$\mathrm{X}_{5}$ : Depth of cut } \\
\hline 132.12 & 129.2 & 103.81 & 2 & 54.77 & 27.38 & 4.93 & 13.2 \\
\hline \multicolumn{8}{|c|}{$\overline{\mathrm{X}_{1} \cdot \mathrm{X}_{2} \text { : Interaction factor [pooled factor] }}$} \\
\hline 117.23 & 127.4 & 120.94 & 4 & 5.88 & - & - & - \\
\hline \multicolumn{8}{|c|}{$\overline{\mathrm{X}_{1} \cdot \mathrm{X}_{5} \text { : Interaction factor }}$} \\
\hline 105.81 & 124.4 & 135.29 & 4 & 49.39 & 12.34 & 2.22 & 11.9 \\
\hline Error & & & 16 & 88.66 & 5.55 & & 21.2 \\
\hline Total & & & 26 & 417.34 & & & 100 \\
\hline
\end{tabular}

Table 10. ANOM results for average surface roughness.

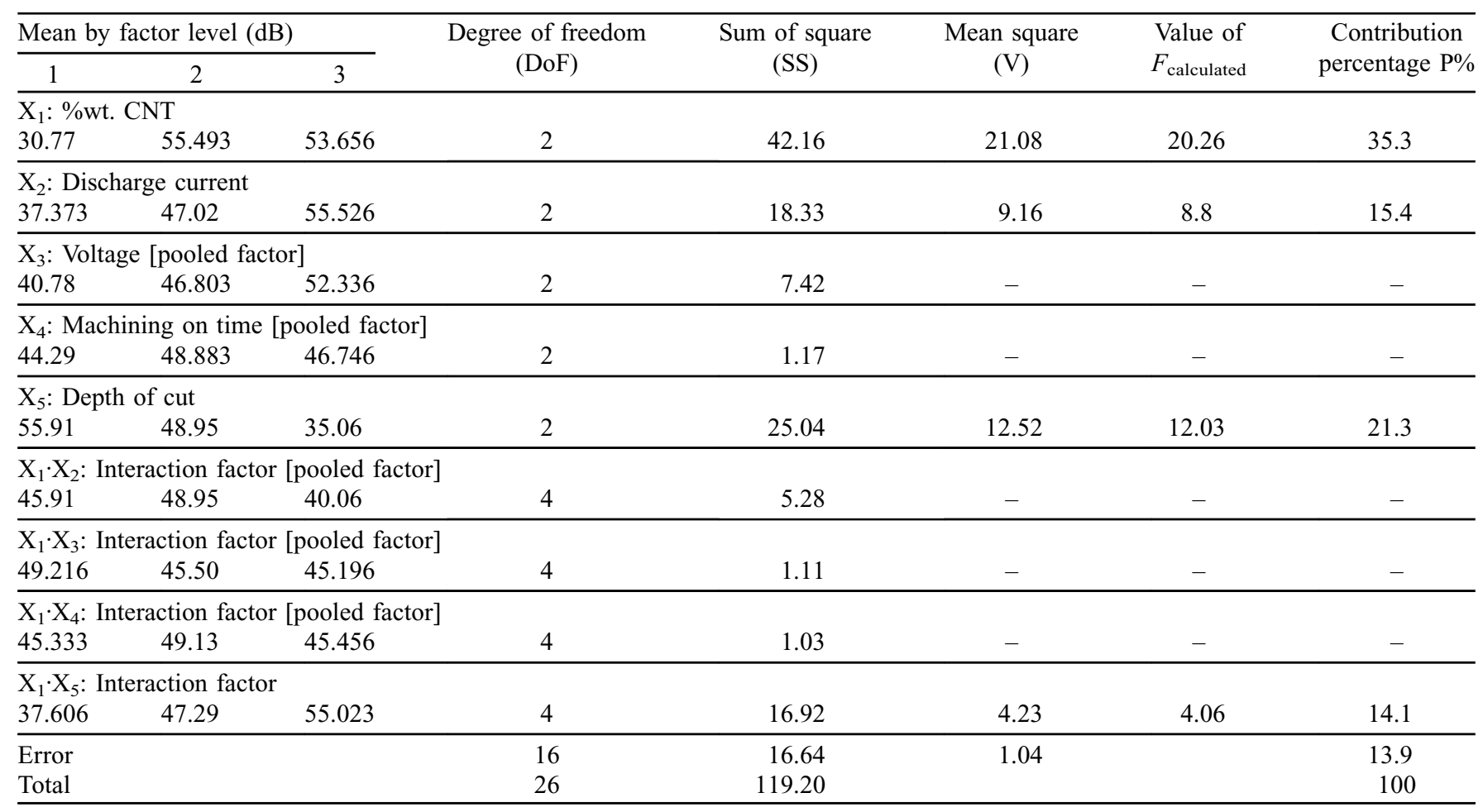

\subsubsection{Optimum levels}

Based on $S / N$ ratio transformation, It is observed that $\mathrm{X}_{11}$, $\mathrm{X}_{23}, \mathrm{X}_{31}$ are the optimal levels of the design parameters for material removal rate which implies percent of CNT at low level, discharge current at high level and volt at low level and this combination gives the best material removal rate within the specified range. On the other hand, it is observed 
Table 11. ANOVA results for average surface roughness.

\begin{tabular}{|c|c|c|c|c|c|c|}
\hline \multicolumn{2}{|c|}{$\begin{array}{l}\text { Standard deviation by factor level } \\
\text { (dB) }\end{array}$} & \multirow[t]{2}{*}{$\begin{array}{l}\text { Degree of freedom } \\
\text { (DoF) }\end{array}$} & \multirow[t]{2}{*}{$\begin{array}{l}\text { Sum of square } \\
\text { (SS) }\end{array}$} & \multirow[t]{2}{*}{$\begin{array}{l}\text { Mean square } \\
\text { (V) }\end{array}$} & \multirow[t]{2}{*}{$\begin{array}{l}\text { Value of } \\
F_{\text {Calculated }}\end{array}$} & \multirow[t]{2}{*}{$\begin{array}{l}\text { Contribution } \\
\text { Percentage } \mathrm{P} \%\end{array}$} \\
\hline 2 & 3 & & & & & \\
\hline \multicolumn{7}{|c|}{$\mathrm{X}_{1}:$ \%wt. CNT [pooled factor] } \\
\hline \multicolumn{7}{|l|}{$\mathrm{X}_{2}$ : Discharge current } \\
\hline $6.1665 \quad 3.0348$ & 2.4245 & 2 & 0.89 & 0.44 & 3.85 & 21.5 \\
\hline \multicolumn{7}{|c|}{$\mathrm{X}_{4}$ : Machining on time [pooled factor] } \\
\hline $4.1781 \quad 3.1851$ & 4.2625 & 2 & 0.07 & - & - & - \\
\hline \multicolumn{7}{|c|}{$\mathrm{X}_{5}:$ Depth of cut [pooled factor] } \\
\hline $3.6736 \quad 3.9190$ & 4.0332 & 2 & 0.007 & - & - & - \\
\hline \multicolumn{7}{|c|}{$\mathrm{X}_{1} \cdot \mathrm{X}_{2}$ : Interaction factor [pooled factor] } \\
\hline \multicolumn{7}{|c|}{$\mathrm{X}_{1} \cdot \mathrm{X}_{4}$ : Interaction factor [pooled factor] } \\
\hline $3.0025 \quad 4.223$ & 4.3994 & 4 & 0.128 & - & - & - \\
\hline \multicolumn{7}{|c|}{$\mathrm{X}_{1} \cdot \mathrm{X}_{5}$ : Interaction factor } \\
\hline $2.2928 \quad 3.102$ & 6.2308 & 4 & 0.961 & 0.24 & 2.1 & 23.5 \\
\hline Error & & 20 & 2.295 & 0.114 & & 55 \\
\hline Total & & 26 & 4.15 & & & 100 \\
\hline
\end{tabular}

Table 12. Results of the confirmation experiment for $S / N$ ratios values.

\begin{tabular}{lcc}
\hline & & Material removal rate \\
\cline { 2 - 3 } & Prediction & Experiment \\
\hline Optimal levels & $\mathrm{X}_{11} \cdot \mathrm{X}_{23} \cdot \mathrm{X}_{31}$ & $\mathrm{X}_{11} \cdot \mathrm{X}_{23} \cdot \mathrm{X}_{31}$ \\
Material removal rate $S / N$ ratio $(\mathrm{dB})$ & -27.986 & -28.622 \\
\hline & Wear electrode ratio & $\mathrm{X}_{13} \cdot \mathrm{X}_{23}$ \\
\hline Optimal levels & $\mathrm{X}_{13} \cdot \mathrm{X}_{23}$ & -0.55 \\
Wear electrode ratio $S / N$ ratio $(\mathrm{dB})$ & -0.65 & \\
\hline & Surface roughness & $\mathrm{X}_{11} \cdot \mathrm{X}_{21} \cdot \mathrm{X}_{53}$ \\
\hline Optimal levels & $\mathrm{X}_{11} \cdot \mathrm{X}_{21} \cdot \mathrm{X}_{53}$ & -6.68 \\
Surface roughness $S / N$ ratio $(\mathrm{dB})$ & -6.01 & \\
\hline
\end{tabular}

Table 13. Results of the confirmation experiment for mean values.

\begin{tabular}{lcr}
\hline & & Material removal rate \\
\cline { 2 - 3 } & Prediction & Experiment \\
\hline Optimal levels & $\mathrm{X}_{11} \cdot \mathrm{X}_{23} \cdot \mathrm{X}_{31}$ & $\mathrm{X}_{11} \cdot \mathrm{X}_{23} \cdot \mathrm{X}_{31}$ \\
0.037 & 0.030 & $\mathrm{X}_{13} \cdot \mathrm{X}_{23}$ \\
\hline Material removal rate mean values & Wear electrode ratio & 1.034 \\
\hline Optimal levels & $\mathrm{X}_{13} \cdot \mathrm{X}_{23}$ & 1.039 \\
\hline Wear electrode ratio mean values & Surface Roughness & $\mathrm{X}_{11} \cdot \mathrm{X}_{21} \cdot \mathrm{X}_{53}$ \\
\hline & $\mathrm{X}_{11} \cdot \mathrm{X}_{21} \cdot \mathrm{X}_{53}$ & 1.867 \\
\hline Optimal levels & 1.086 & \\
Surface roughness mean values & & \\
\hline
\end{tabular}


that $\mathrm{X}_{13}, \mathrm{X}_{23}$ are the optimal levels of the design parameters for electrode wear ratio which implies percent of CNT at high level, discharge current at high level and depth of cut at low level and this combination gives the best electrode wear ratio within the specified range. Finally, it is observed that $X_{11}$, $\mathrm{X}_{21}$ and $\mathrm{X}_{53}$ are the optimal levels of the design parameters for surface roughness ratio which implies percent of CNT at low level, discharge current at low level and depth of cut at high level and this combination gives the best surface roughness within the specified range. Using mean values, It is observed that $X_{11}, X_{23}$ and $X_{31}$ are the optimal levels of the design parameters for material removal rate which implies percent of CNT at low level, discharge current at high level and voltage at low level and this combination gives the best material removal rate within the specified range. On the other hand, it is observed that $X_{13}$ and $X_{23}$ are the optimal levels of the design parameters for electrode wear ratio which implies percent of CNT at high level, discharge current at high level and depth of cut at low level and this combination gives the best wear electrode ratio within the specified range. It is observed that $X_{11}, X_{21}$ and $X_{53}$ are the optimal levels of the design parameters for surface roughness ratio which implies percent of CNT at low level, discharge current at low level and depth of cut at high level and this combination gives the best surface roughness within the specified range.

\subsubsection{Verification of experimental results}

Once the optimal level of design parameters is selected, the final step is to verify the improvement of quality characteristics using the optimal level of design parameters. The estimated optimal level of parameters is calculated as:

$$
Y_{\text {Predicted }}=Y_{\text {Mean }}+\sum\left[Y_{i}-Y_{\text {mean }}\right] \text {, }
$$

$Y_{i}$ is the mean ( $S / N$ ratio, mean, and standard deviation) response at optimal level for the main design parameters that affect the quality characteristics, and $Y_{\text {mean }}$ is the total mean ( $\mathrm{S} / \mathrm{N}$ ratio, mean, and standard deviation) response. Tables 12 and 13 show the comparison of the predicted and actual material removal rate, wear electrode ratio, and average surface roughness. Good agreement between the predicted and actual ( $S / N$ ratio and mean) responses is observed. Surface roughness response has the highest deviation between responses for both mean and $S / N$ ratio.

A look at Tables 12 and 13 indicates:

(a) Using material removal rate, both experimental and predicted responses are close.

(b) A similar agreement is observed based on mean response. The predicted average surface roughness is lower than the experimental results. All results are repeated using another surface roughness device located at Faculty of Engineering, Cairo University (Sutronic 3P). Results validate our earlier measurements. Deviations observed are mainly due to the orthogonal array employed. There are 5 variables at 3 levels $\left(3^{5}=243 \mathrm{OA}\right)$. The L243OA is very expensive array to employ and a decision to employ L27OA is taken to reduce cost of experimentation. The $\mathrm{L} 27 \mathrm{OA} / \mathrm{L} 243 \mathrm{OA}$ is equivalent to $1 /$ 9 of the experiments required. Of course, with this choice, more interactions could have been estimated.

\subsection{Response Surface Methodology (RSM)}

Response Surface Methodology attempts to analyze the influence of the independent variables on a specific response. The purpose of mathematical models relates the process responses to process variables. The mathematical model commonly used for the process responses is represented as:

$$
Y=F\left(\mathrm{X}_{1}, \mathrm{X}_{2} \ldots\right)+\varepsilon,
$$

where $\mathrm{X}_{1}, \mathrm{X}_{2} \ldots \mathrm{X}_{n}$ are process parameters and $\varepsilon$ is the error which is normally distributed about the observed response $Y$. Coefficients of process parameters using RSM is represented as:

$$
[B]=\text { Inverse }\left([Z]^{\mathrm{T}} *[Z]\right) *[Z]^{\mathrm{T}} *[F],
$$

where $[B]$ : array of coefficients of process parameters, $[Z]$ : orthogonal array with values of selected process parameters, $[F]$ : array with values of measured response, and $[Z]^{\mathrm{T}}$ : transpose array of $[Z]$. In order to judge the accuracy of the predicted model, Percentage of deviation $\varphi_{i}$ and average percentage of deviation $\varphi^{\wedge}$ are defined as:

$$
\varphi_{i}=\left[\left(\text { Absolute }\left[R_{\text {measured }}-R_{\text {predicted }}\right]\right) /\left(R_{\text {measured }}\right)\right],
$$

where $\varphi_{i}$ is percentage deviation of single sample data, $R_{\text {measured }}$ is measured response and $R_{\text {predicted }}$ is predicted response,

$$
\varphi^{\wedge}=\left(\sum \varphi_{i}\right) / n,
$$

where $\varphi^{\wedge}$ is average percentage deviation of all sample data and $\mathrm{n}$ is the size of sample data.

\subsubsection{Mathematical models for (MRR)}

A mathematical model is developed for the material removal rate based on $S / N$ ratio as in Eq. (10). The model deviation varies from $0.26 \%$ to $20.73 \%$. Figure 2 shows the estimated three-dimensional surface for material removal rate response values $(\mathrm{dB})$ as function of $\mathrm{X}_{1}, \mathrm{X}_{2}, \mathrm{X}_{3}$, and $\mathrm{X}_{1} \cdot \mathrm{X}_{5}$. In all these figures, two of the four variables are held constant at center points.

$$
\begin{aligned}
\mathrm{MRR}_{1}= & -28.713-231.93 * \mathrm{X}_{1}+1.980 * \mathrm{X}_{2} \\
& -0.261 * \mathrm{X}_{3}+146.11 \mathrm{X}_{1} * \mathrm{X}_{5} .
\end{aligned}
$$

A mathematical model is developed for the material removal rate based on mean in Eq. (11). The model deviation varies from $2.19 \%$ to $66.82 \%$. Figure 3 shows the estimated three-dimensional surface response for material removal rate as function of $X_{1}, X_{2}$ and $X_{3}$ respectively.

$$
\begin{aligned}
\mathrm{MRR}_{2}= & 0.018953-0.36152 * \mathrm{X}_{1}+0.00314 * \mathrm{X}_{2} \\
& -0.00024 * \mathrm{X}_{3}+0.299020 \mathrm{X}_{1} * \mathrm{X}_{5} .
\end{aligned}
$$



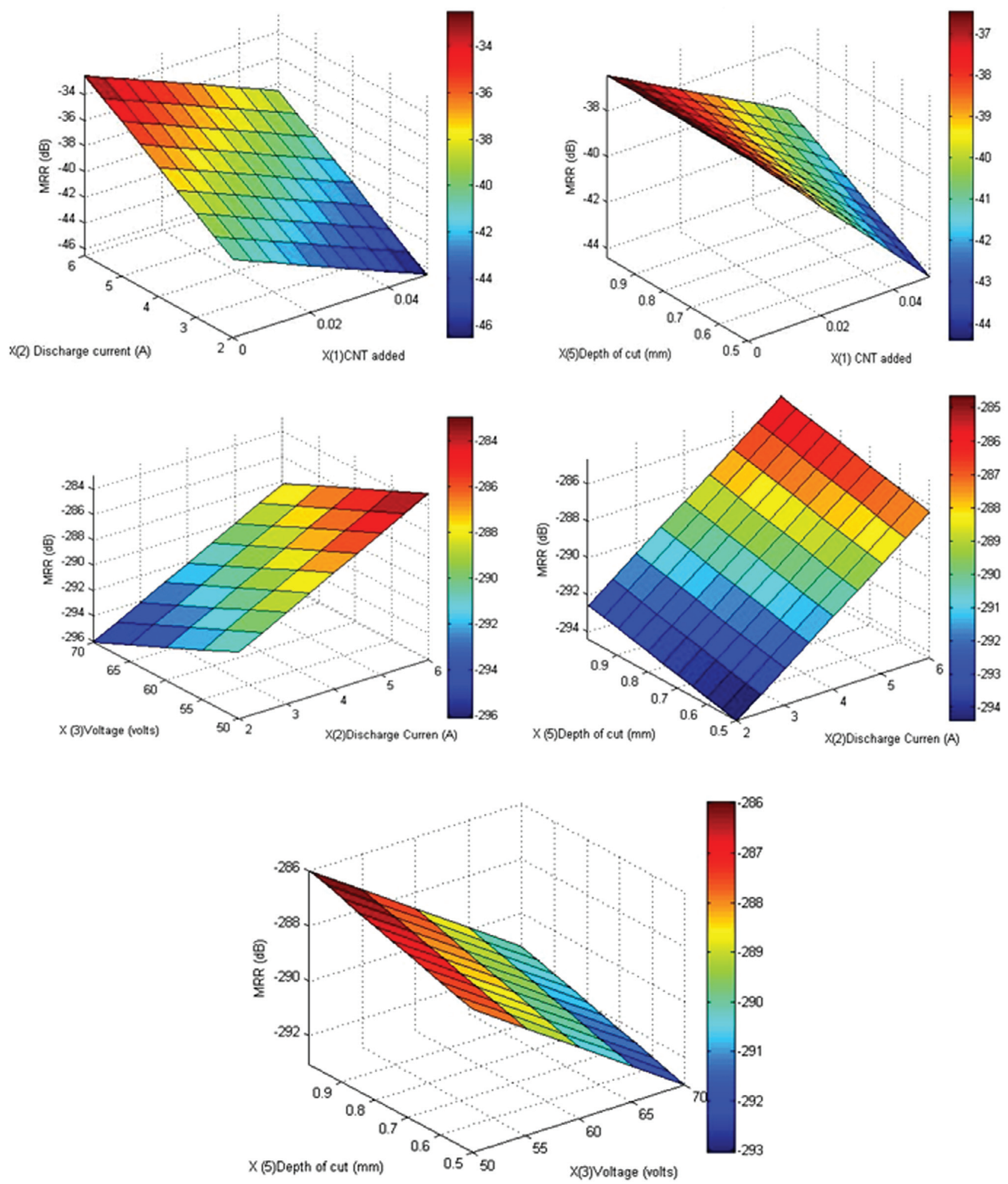

Figure 2. Effect of EDM process parameters on MRR (dB). 


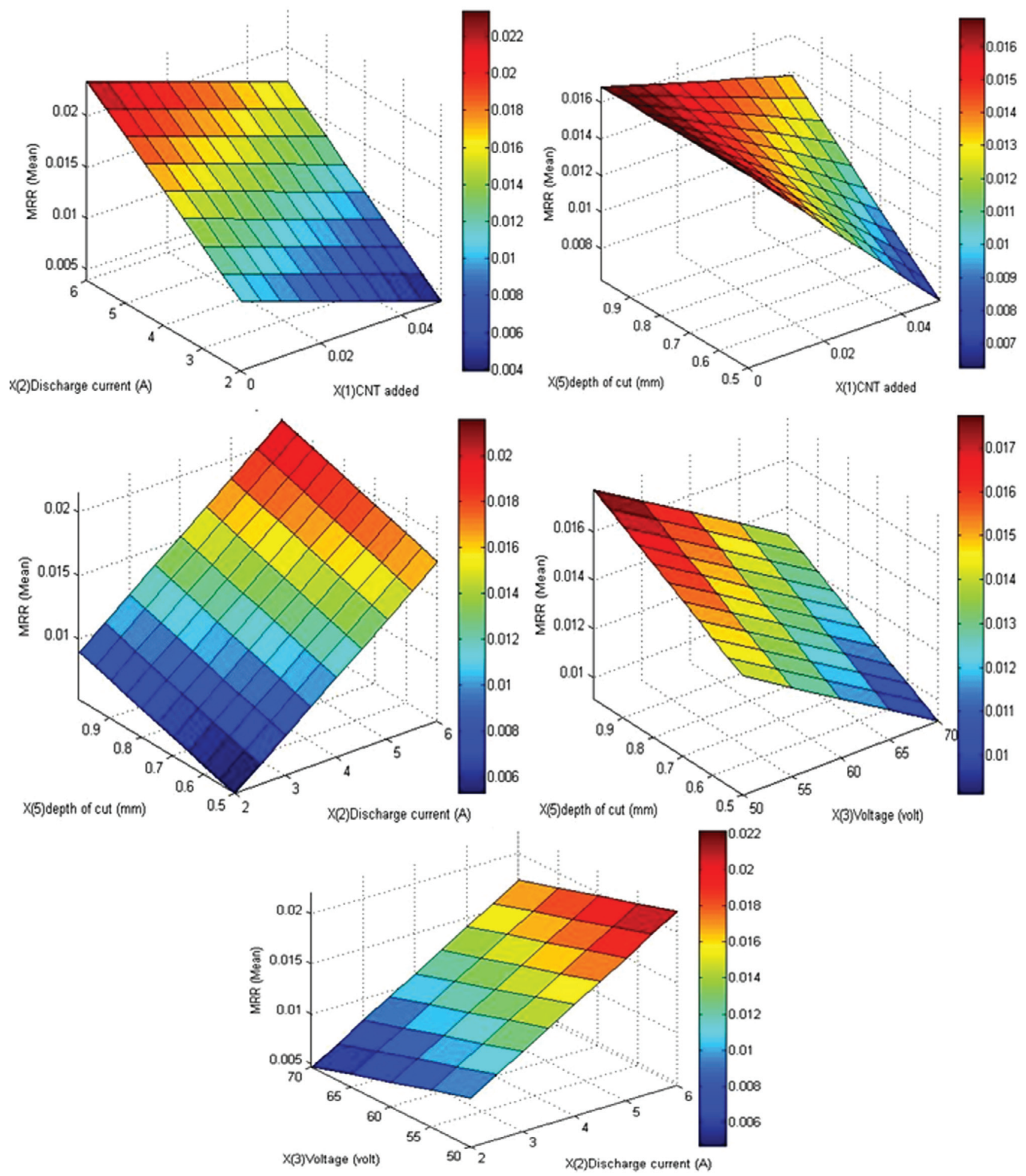

Figure 3. Effect of EDM process parameters on mean MRR.

Finally, a mathematical model is developed for the material removal rate based on standard deviations in Eq. (12). Figure 4 shows the estimated three-dimensional surface for material removal rate as function of $\mathrm{X}_{1}, \mathrm{X}_{2}$ and $\mathrm{X}_{3}$, respectively.

$$
\begin{aligned}
\mathrm{MRR}_{3}= & 0.0042-0.0738 * \mathrm{X}_{1}-0.00099 * \mathrm{X}_{2} \\
& -0.000009 * \mathrm{X}_{3}+1.37 *\left(\mathrm{X}_{1}\right)^{2}+0.00018 \\
& *\left(\mathrm{X}_{2}\right)^{2}-0.0000003 *\left(\mathrm{X}_{3}\right)^{2} .
\end{aligned}
$$



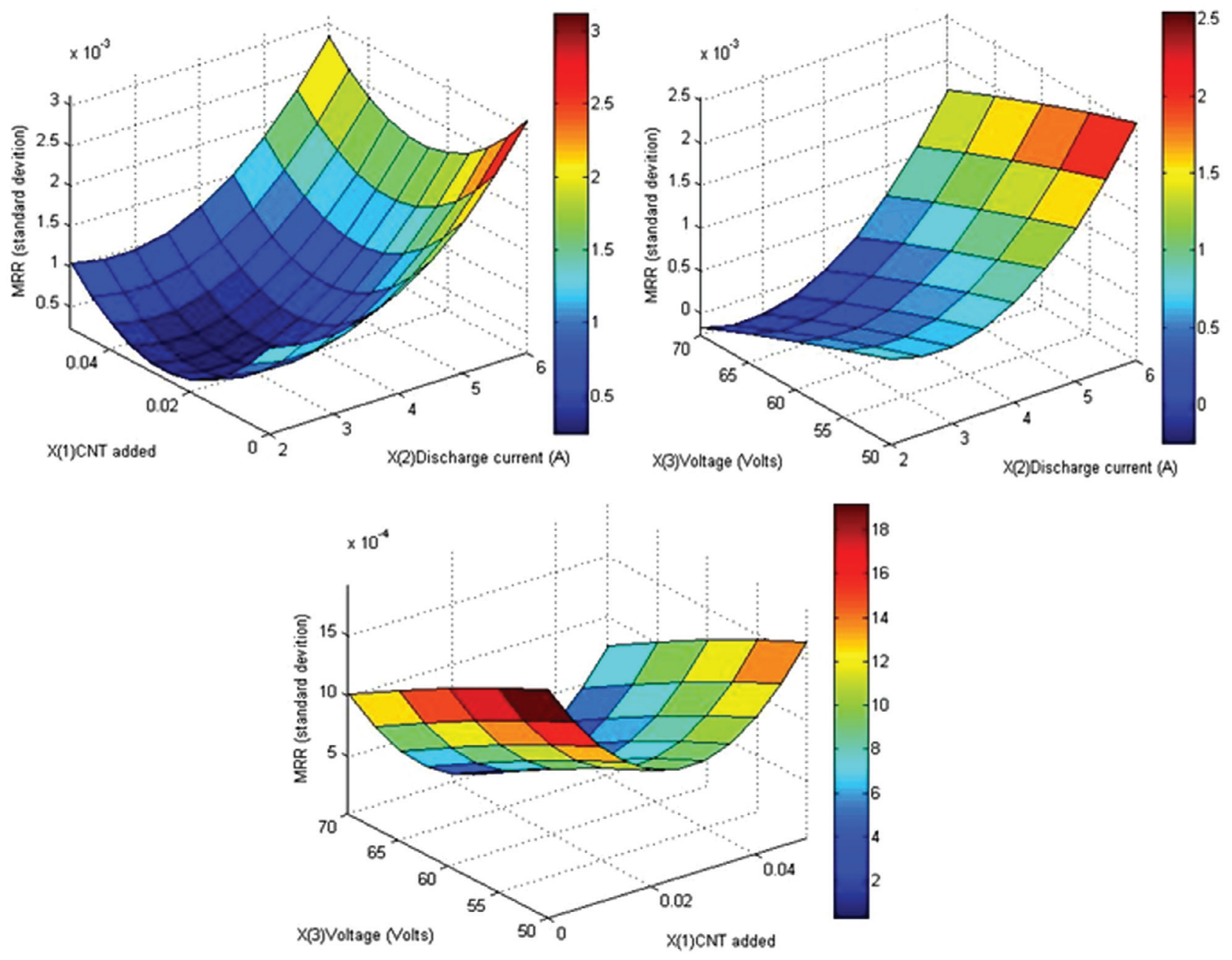

Figure 4. Effect of EDM process parameters on standard deviation of MRR.
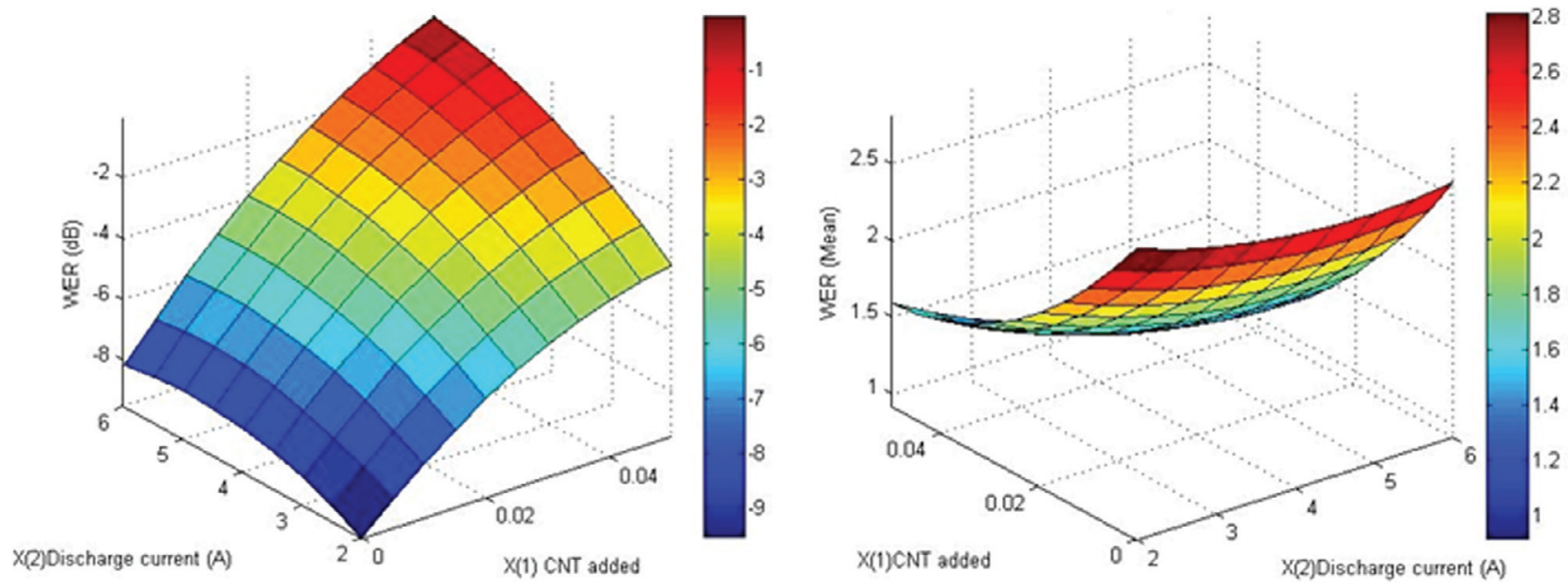

Figure 5. Effect of EDM process parameters on WER (dB). 


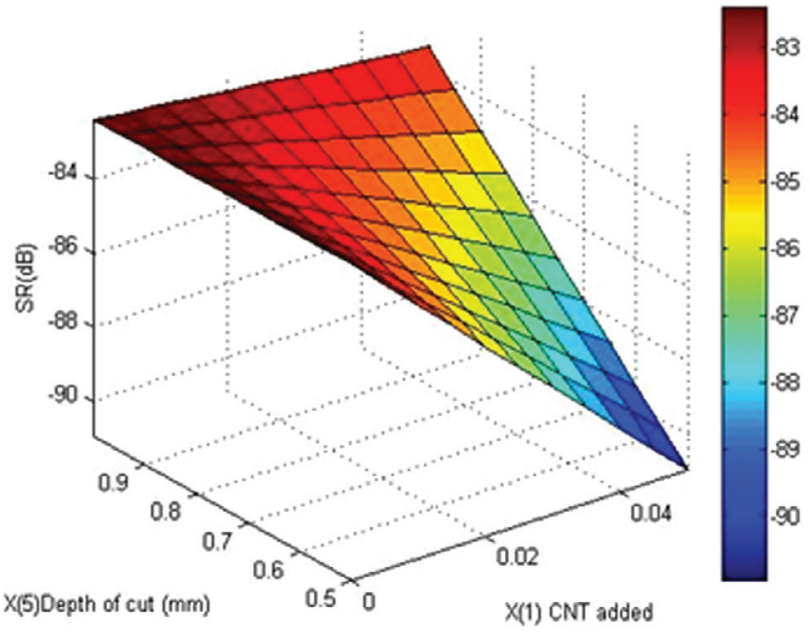

Figure 6. Effect of EDM process parameters on surface roughness.

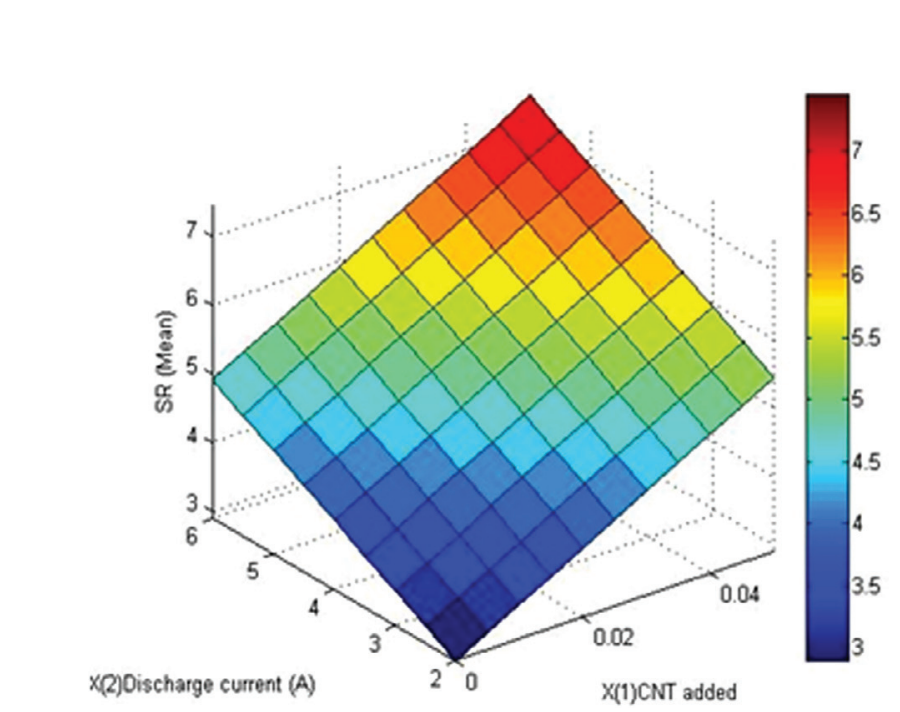

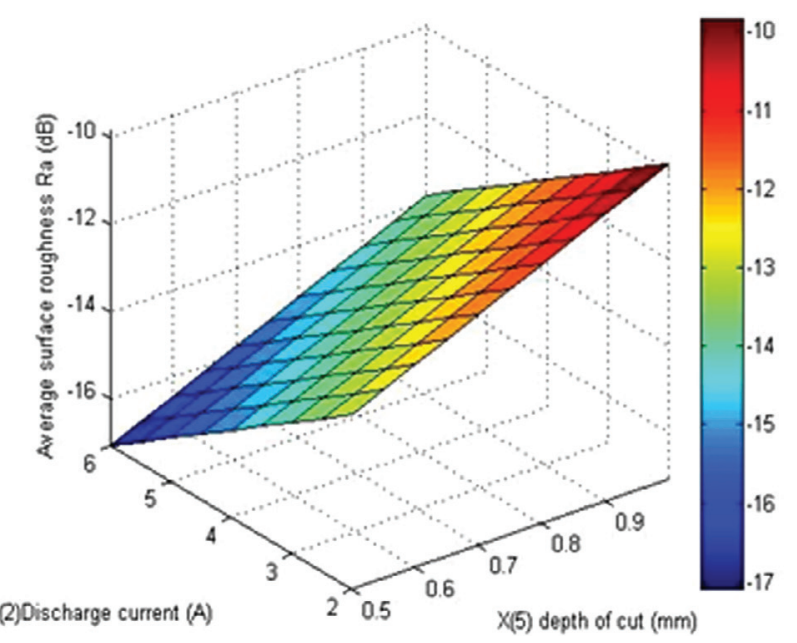

X(2)Discharge current (A)

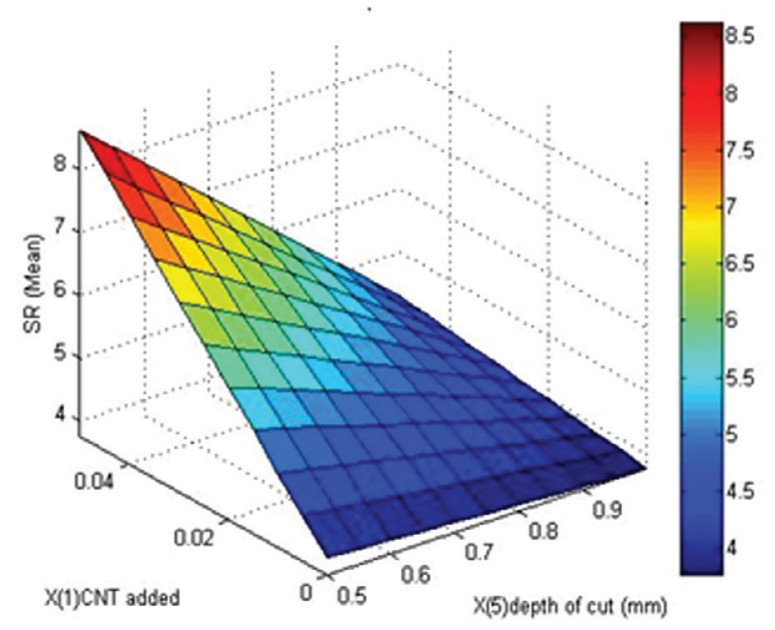

Figure 7. Effect of EDM process parameters on mean surface roughness.

\subsubsection{Mathematical models for EWR}

A mathematical model is developed for electrode wear ratio based on $S / N$ ratio as in Eq. (13). The model deviation varies from $2.28 \%$ to $95.51 \%$. Figures 5 shows the estimated three-dimensional surface and contour plots for wear electrode ratio as function of $\mathrm{X}_{1}$ and $\mathrm{X}_{2}$.

$$
\begin{aligned}
\mathrm{EWR}_{1}= & 3.314-42.89 * \mathrm{X}_{1}-0.313 * \mathrm{X}_{2}+455 \\
& *\left(\mathrm{X}_{1}\right)^{2}+0.032 *\left(\mathrm{X}_{1}\right)^{2}-2.21 * \mathrm{X}_{1} * \mathrm{X}_{2} .
\end{aligned}
$$

A mathematical model is developed for electrode wear ratio based on mean as in Eq. (14). The model deviation varies from $3.26 \%$ to $45.65 \%$. Figure 5 shows the estimated threedimensional surface for wear electrode ratio as function of $\mathrm{X}_{1}$ and $\mathrm{X}_{2}$.

$$
\begin{aligned}
\mathrm{EWR}_{2}= & 3.314-42.89 * \mathrm{X}_{1}-0.313 * \mathrm{X}_{2}+455 \\
& *\left(\mathrm{X}_{1}\right)^{2}+0.032 *\left(\mathrm{X}_{1}\right)^{2}-2.21 * \mathrm{X}_{1} * \mathrm{X}_{2}
\end{aligned}
$$

Finally, a mathematical model is developed for electrode wear ratio based on standard deviations in Eq. (15).

$$
\begin{aligned}
\mathrm{EWR}_{3}= & 1.56-24.21 * \mathrm{X}_{1}-0.32 * \mathrm{X}_{2}+185.78 \\
& *\left(\mathrm{X}_{1}\right)^{2}+0.028 *\left(\mathrm{X}_{2}\right)^{2}+1.3 * \mathrm{X}_{1} * \mathrm{X}_{2}
\end{aligned}
$$

\subsubsection{Mathematical models for average surface roughness $(R a)$}

A mathematical model is developed for average surface roughness based on $S / N$ ratio as in Eq. (16). The model deviation varies from $0.486 \%$ to $42.76 \%$. Figure 6 shows the 
Table 14. Results of single objective optimization for all formulations.

\begin{tabular}{|c|c|c|c|}
\hline & 1st Formulation & 2nd Formulation & 3rd Formulation \\
\hline$X^{*}$ & $\left(X_{1}, X_{2}, X_{3}, X_{5}\right)=(0.001,5.9,50.1,1)$ & $\left(X_{1}, X_{2}, X_{5}\right)=(0,2,1)$ & $\left(X_{1}, X_{2}\right)=(0.05,5.99)$ \\
\hline$F^{*}$ & 30.11 & 8.82 & 0.025 \\
\hline \multirow[t]{2}{*}{ Number of iterations to convergence } & 51 & 52 & 51 \\
\hline & 4th Formulation & 5th Formulation & 6th Formulation \\
\hline$X^{*}$ & $\left(X_{1}, X_{2}, X_{3}, X_{5}\right)=(0.021,3.2,66.5,1)$ & $\left(\mathrm{X}_{1}, \mathrm{X}_{2}\right)=(0.05,2)$ & $\left(X_{1}, X_{2}, X_{5}\right)=(0,2,1)$ \\
\hline$F^{*}$ & 186603 & 399.91 & 2.75 \\
\hline Number of iterations to convergence & 73 & 51 & 51 \\
\hline
\end{tabular}

Where $X^{*}$ denotes optimum values for selected control parameters. $F^{*}$ denotes optimum response value for each objective function.

estimated three-dimensional surface for average surface roughness response values as function of $\mathrm{X}_{1}, \mathrm{X}_{2}$ and $\mathrm{X}_{5}$ respectively.

$$
\begin{aligned}
R a_{1}= & -6.202-321.283 * \mathrm{X}_{1}-1.009 * \mathrm{X}_{2} \\
& -1.202 * \mathrm{X}_{5}+300.492 * \mathrm{X}_{1} * \mathrm{X}_{5} .
\end{aligned}
$$

Finally, a mathematical model is developed for average surface roughness based on mean as in Eq. (17). The model deviation varies from $1.85 \%$ to $47.77 \%$. Figure 7 shows the estimated three-dimensional surface for average surface roughness response values as function of $X_{1}, X_{2}$ and $X_{5}$ respectively.

$$
\begin{aligned}
R a_{2}= & 2.32+172.77 * \mathrm{X}_{1}+0.504 * \mathrm{X}_{2}-0.569 \\
& * \mathrm{X}_{5}-162.54 * \mathrm{X}_{1} * \mathrm{X}_{5} .
\end{aligned}
$$

\subsection{Optimization of EDM process}

Models developed for material removal rate, electrode wear ratio and average surface roughness are optimized subject to process constrains. MATLAB Optimization Toolbox (Constrained Minimization using Genetic Algorithm) is employed to obtain optimum process settings. The Genetic Algorithm (Random based optimization techniques) is a model of machine learning which derives its behavior from a metaphor of the processes of evolution in nature. This is done by the creation within a machine of a population of individuals represented by CHROMOSOMEs, in essence a set of character strings that are analogous to the base- 4 chromosomes that seen in our own DNA. Individuals in the population then go through a process of evolution [8].

(A) First Formulation: The first formulation is to maximize material removal rate (based on $S / N$ ratio) subject to process constraints as:

$$
\begin{aligned}
\operatorname{Max} M R R= & -28.71-231.93 * \mathrm{X}_{1}+1.980 * \mathrm{X}_{2} \\
& -0.261 * \mathrm{X}_{3}+146.11 * \mathrm{X}_{1} * \mathrm{X}_{5} .
\end{aligned}
$$

\section{Subject To:}

Constraint 1: $0 \leq \mathrm{X}_{1} \leq 0.05$.

Constraint 2: $2 \leq \mathrm{X}_{2} \leq 6$.

Constraint 3: $50 \leq \mathrm{X}_{3} \leq 70$.

Constraint 4: $0.5 \leq \mathrm{X}_{5} \leq 1$.

$$
\mathrm{X}_{1}, \mathrm{X}_{2}, \mathrm{X}_{3}, \mathrm{X}_{5} \geq 0
$$

(B) Second Formulation: The second formulation is to maximize average surface roughness (based on $S / N$ ratio) subject to process constraints as:

$$
\begin{aligned}
\operatorname{Max} R a= & -6.202-321.283 * \mathrm{X}_{1}-1.009 * \mathrm{X}_{2} \\
& -1.202 * \mathrm{X}_{5}+300.492 * \mathrm{X}_{1} * \mathrm{X}_{5} .
\end{aligned}
$$

Subject To:

Constraint 1: $0 \leq \mathrm{X}_{1} \leq 0.05$.

Constraint 2: $2 \leq \mathrm{X}_{2} \leq 6$.

Constraint 3: $0 . \overline{5} \leq \mathrm{X}_{5} \leq 1$.

$$
\mathrm{X}_{1}, \mathrm{X}_{2}, \mathrm{X}_{5} \geq 0
$$

(C) Third Formulation: The third formulation is to maximize electrode wear ratio (based on $S / N$ ratio) subject to process constraints as:

$$
\begin{aligned}
\operatorname{Max} \text { WER }= & -12.39+170.61 * \mathrm{X}_{1}+1.811 * \mathrm{X}_{2} \\
& -1647.90 *\left(\mathrm{X}_{1}\right)^{2}-0.184 *\left(\mathrm{X}_{2}\right)^{2}+12.38 \\
& * \mathrm{X}_{1} * \mathrm{X}_{2} .
\end{aligned}
$$

Subject To:

Constraint 1: $0 \leq \mathrm{X}_{1} \leq 0.05$.

Constraint 2: $2 \leq \mathrm{X}_{2} \leq 6$.

$$
\mathrm{X}_{1}, \mathrm{X}_{2} \geq 0 \text {. }
$$

(D) Fourth Formulation: The fourth formulation is to maximize mean of material removal rate to standard deviation of material removal rate subject to process constraints as: 

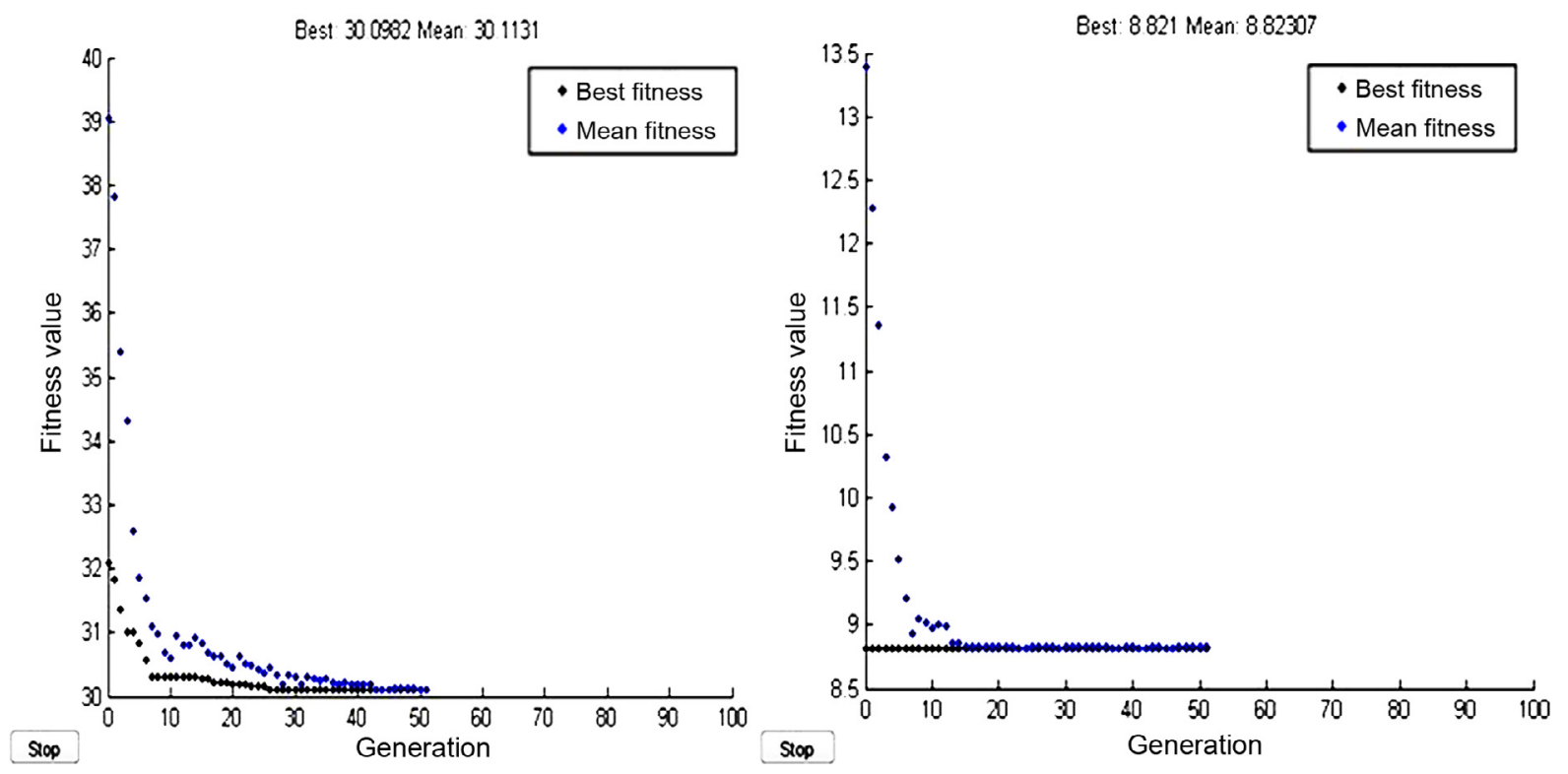

Figure 8. Progress of fitness value vs. number of iterations: $1^{\text {st }}$ formulation and $2^{\text {nd }}$ formulation.
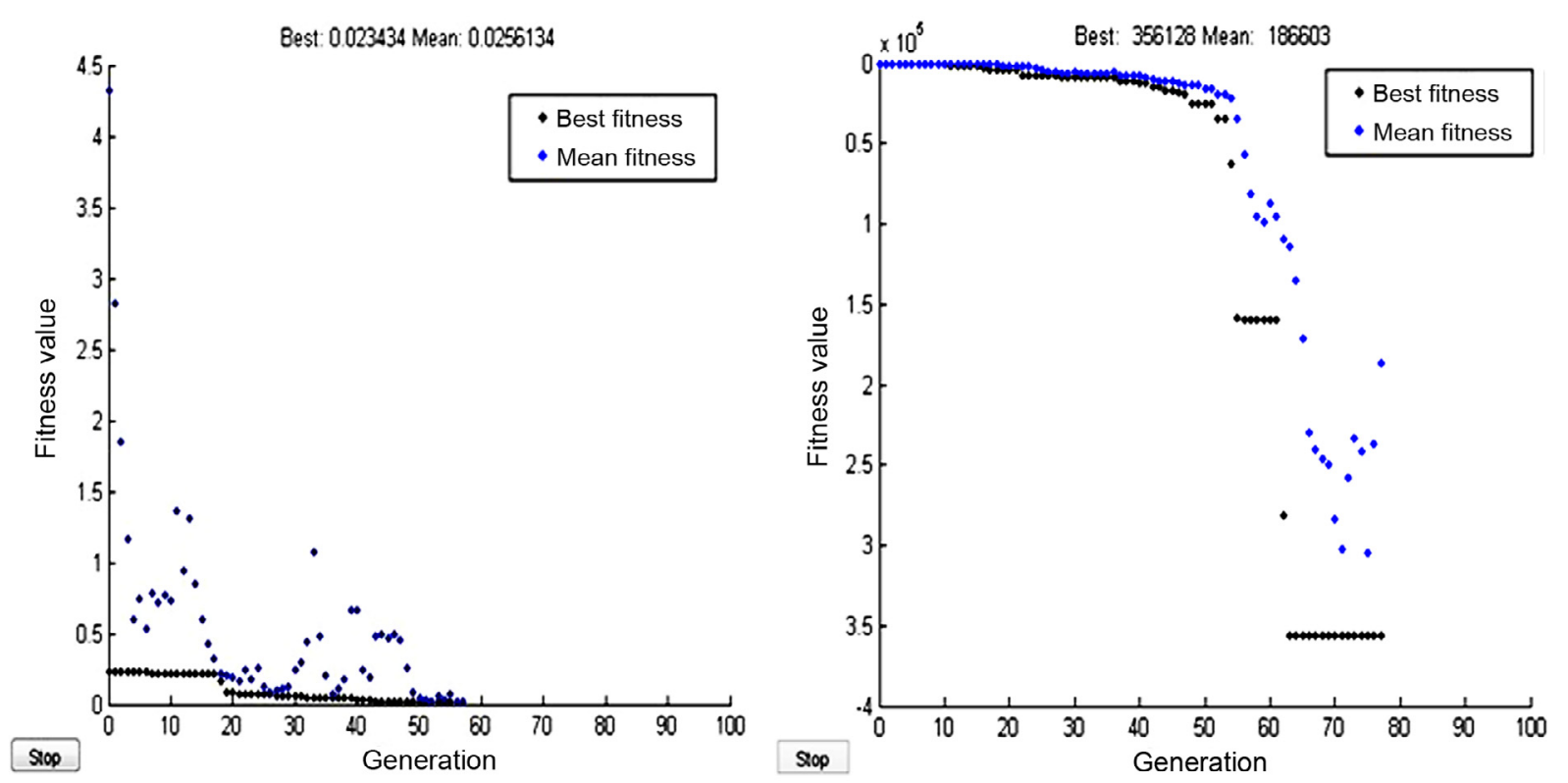

Figure 9. Progress of fitness value vs. number of iterations: $3^{\text {rd }}$ formulation and $4^{\text {th }}$ formulation.

$$
\begin{aligned}
\operatorname{Max} \mu_{\mathrm{MRR}} / \sigma_{\mathrm{MRR}}= & \left(\left(0.018953-0.36152 * \mathrm{X}_{1}+0.00314\right.\right. \\
& * \mathrm{X}_{2}-0.00024 * \mathrm{X}_{3}+0.299020 * \mathrm{X}_{1} \\
& \left.* \mathrm{X}_{5}\right) /\left(0.0042-0.0738 * \mathrm{X}_{1}\right. \\
& -0.00099 * \mathrm{X}_{2}-0.000009 * \mathrm{X}_{3} \\
& +1.37 *\left(\mathrm{X}_{1}\right)^{2}+0.00018 *\left(\mathrm{X}_{2}\right)^{2} \\
& \left.\left.-0.0000003 *\left(\mathrm{X}_{3}\right)^{2}\right)\right) .
\end{aligned}
$$

Subject To:

Constraint 1: $0 \leq \mathrm{X}_{1} \leq 0.05$.

Constraint 2: $2 \leq \mathrm{X}_{2} \leq 6$.

Constraint 3: $50 \leq \mathrm{X}_{3} \leq 70$.

Constraint 4: $0.5 \leq \mathrm{X}_{5} \leq 1$.

$$
\mathrm{X}_{1}, \mathrm{X}_{2}, \mathrm{X}_{3}, \mathrm{X}_{5} \geq 0
$$



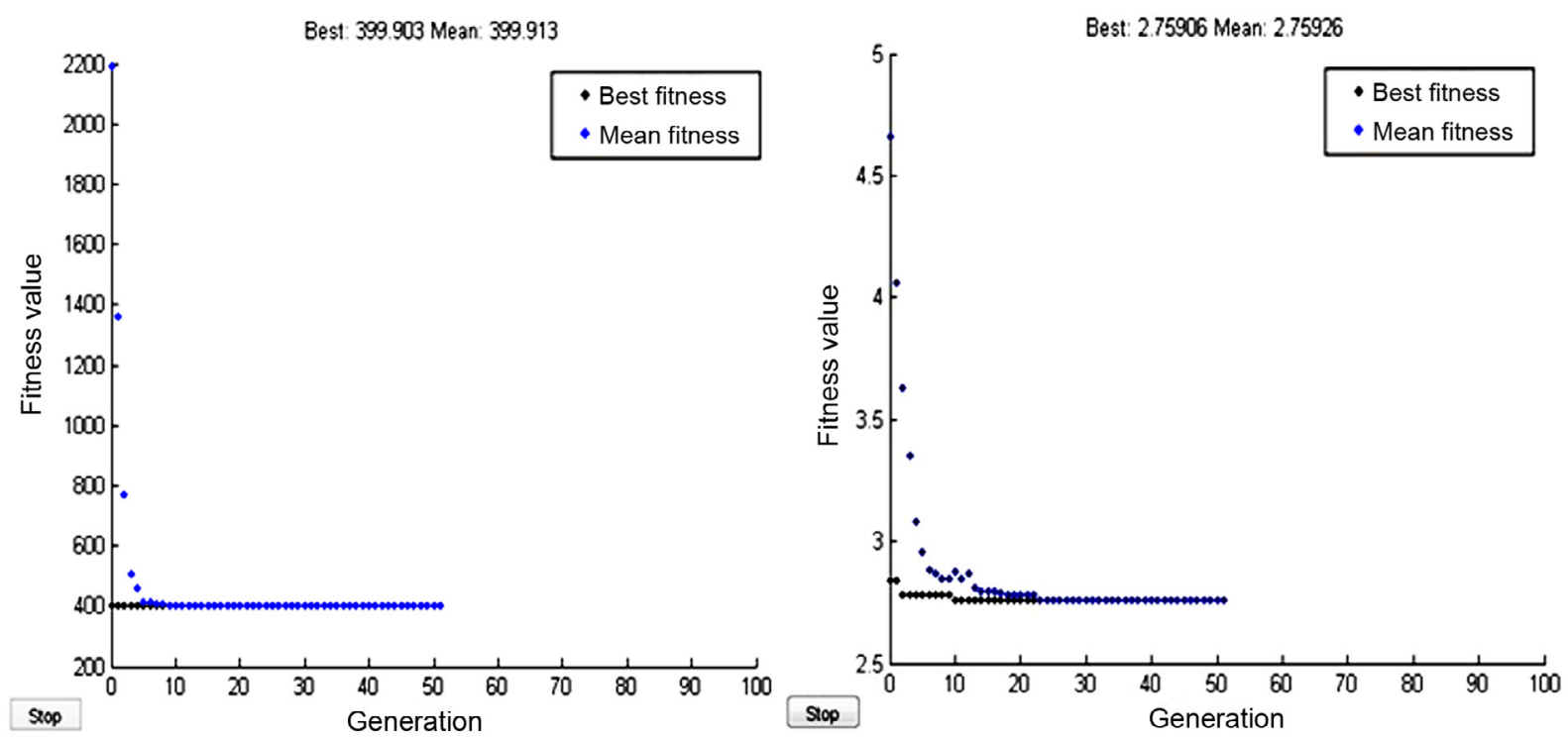

Figure 10. Progress of fitness value vs. number of iterations: $5^{\text {th }}$ formulation and $6^{\text {th }}$ formulation.

(E) Fifth Formulation: The fourth formulation is to maximize mean of electrode wear ratio to standard deviation of electrode wear ratio subject to process constraints as:

$$
\begin{aligned}
\operatorname{Max} \mu_{\mathrm{WER}} / \sigma_{\mathrm{WER}}= & \left(\left(3.314-42.89 * \mathrm{X}_{1}-0.313 * \mathrm{X}_{2}\right.\right. \\
& +455 *\left(\mathrm{X}_{1}\right)^{2}+0.032 *\left(\mathrm{X}_{2}\right)^{2} \\
& \left.-2.21 * \mathrm{X}_{1} * \mathrm{X}_{2}\right) /\left(1.56-24.21 * \mathrm{X}_{2}\right. \\
& -0.32 * \mathrm{X}_{2}+185.78 *\left(\mathrm{X}_{1}\right)^{2} \\
& \left.\left.+0.028 *\left(\mathrm{X}_{2}\right)^{2}+1.3 * \mathrm{X}_{1} * \mathrm{X}_{2}\right)\right) .
\end{aligned}
$$

Subject To:

Constraint 1: $0 \leq \mathrm{X}_{1} \leq 0.05$.

Constraint 2: $2 \leq \mathrm{X}_{2} \leq 6$.

$$
\mathrm{X}_{1}, \mathrm{X}_{2} \geq 0
$$

(F) Sixth Formulation: The Sixth formulation is to minimize average surface roughness (mean values) subject to process constraints as:

$$
\begin{aligned}
\text { Minimize } R a= & 2.32+172.77 * \mathrm{X}_{1}+0.504 * \mathrm{X}_{2} \\
& -0.569 * \mathrm{X}_{5}-162.54 * \mathrm{X}_{1} * \mathrm{X}_{5} .
\end{aligned}
$$

Subject To:

Constraint 1: $0 \leq \mathrm{X}_{1} \leq 0.05$.

Constraint 2: $2 \leq \mathrm{X}_{2} \leq 6$.

Constraint 3: $0.5 \leq \mathrm{X}_{5} \leq 1$.

$$
\mathrm{X}_{1}, \mathrm{X}_{2}, \mathrm{X}_{5} \geq 0
$$

Several parameters affect the performance of Genetic Algorithms. These are the mutation rate, population size, number of generation and cross over rate. Here, the cross over rate (Y1), the population size (Y2), and number of generations (Y3) are defined as 20, 0.8 and 100 respectively. Table 14 gives results of optimization of different formulations. Good agreement is found between Genetic Algorithm results and Taguchi based method (mentioned previously as in optimum levels section).

Figure 8 gives a plot of the progress of material removal rate and average surface roughness (based on $S / N$ ratios) vs. iteration number (the progress shows convergence to the optimum). Figures 9 and 10 are similar plots for the other formulations mentioned previously.

\subsection{Multi-objective optimization for three quality characteristics}

The three quality characteristics models are optimized as a multi-objective optimization subject to process constraints using Genetic Algorithm. The Multi-Objective Optimization Formulations subject to limits on process variables are stated as:

(A) Based on $S / N$ ratio response values:

$$
\begin{aligned}
\operatorname{Maximize} \mathrm{F}_{1}= & \text { Maximize MRR } \\
= & -28.71-231.93 * \mathrm{X}_{1}+1.980 * \mathrm{X}_{2} \\
& -0.261 * \mathrm{X}_{3}+146.11 * \mathrm{X}_{1} * \mathrm{X}_{5} . \\
\text { Maximize } \mathrm{F}_{2}= & \text { Maximize } R a \\
= & -6.202-321.283 * \mathrm{X}_{1}-1.009 * \mathrm{X}_{2} \\
& -1.202 * \mathrm{X}_{5}+300.492 * \mathrm{X}_{1} * \mathrm{X}_{5} .
\end{aligned}
$$


Table 15. Results of Multi-objective optimization for all formulations.

\section{$S / N$ ratio response values}

Values of weighting factors $(\mathrm{C} 1, \mathrm{C} 2, \mathrm{C} 3) \mathrm{C} 1=\mathrm{C} 2=\mathrm{C} 3=0.333333$

$X^{*}$

$F^{*}=[\mathrm{C} 1 \cdot \mathrm{F} 1 *, \mathrm{C} 2 \cdot \mathrm{F} 2 *, \mathrm{C} 3 \cdot \mathrm{F} 3 *]$

$(0.042,6,50,0.99) \quad(40.38,4.77,0.25)$

Mean response values

Values of weighting factors $(\mathrm{C} 1, \mathrm{C} 2, \mathrm{C} 3) \mathrm{C} 1=\mathrm{C} 2=\mathrm{C} 3=0.333333 \quad \frac{X^{*}}{\frac{(0.042,2.02,50,1)}{(0.0035,1.06,0.543)}}$

Where $X^{*}$ denotes Optimum values for selected control parameters. $F^{*}$ denotes optimum response value for each objective function.
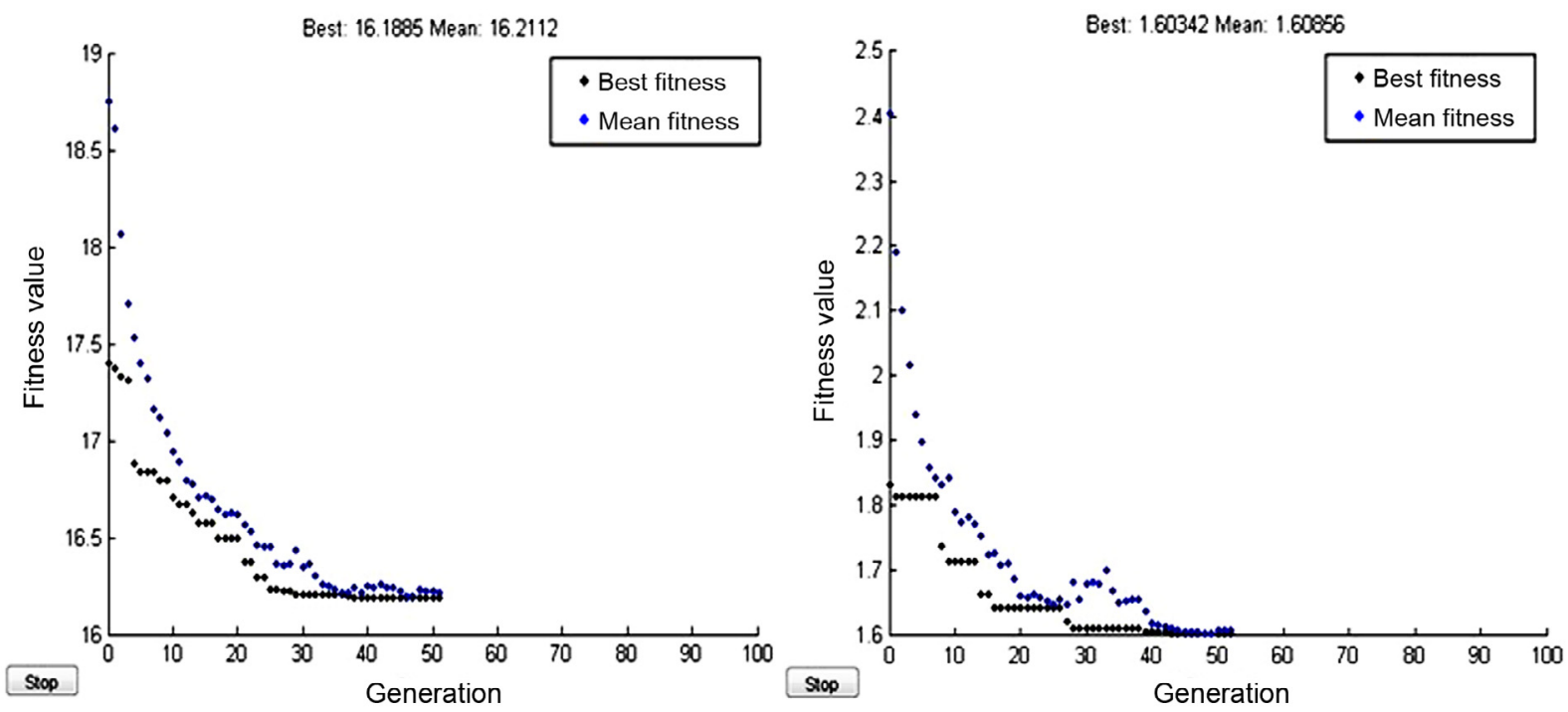

Figure 11. Equal weighted multi-objective optimization for $\mathrm{S} / \mathrm{N}$ and mean values.

$$
\begin{aligned}
\text { Maximize } \mathrm{F}_{3}= & \text { Maximize EWR } \\
= & -12.39+170.61 * \mathrm{X}_{1}+1.811 * \mathrm{X}_{2} \\
& -1647 *\left(\mathrm{X}_{1}\right)^{2}-0.184 *\left(\mathrm{X}_{2}\right)^{2} \\
& +12.38 * \mathrm{X}_{1} * \mathrm{X}_{2} .
\end{aligned}
$$

Subject To:

$0 \leq \mathrm{X}_{1} \leq 0.05 ; 2 \leq \mathrm{X}_{2} \leq 6 ; 50 \leq \mathrm{X}_{3} \leq 70 ; 0.5 \leq \mathrm{X}_{5} \leq 1$

$$
\mathrm{X}_{1}, \mathrm{X}_{2}, \mathrm{X}_{3}, \mathrm{X}_{5} \geq 0
$$

The combined objective function gives equal weight for the three objectives $(\mathrm{C} 1=\mathrm{C} 2=\mathrm{C} 3=0.333333)$ as shown in Eq. (18).

$$
\mathrm{Z}=-0.333 * \mathrm{~F}_{1}-0.333 * \mathrm{~F}_{2}-0.333 * \mathrm{~F}_{3} .
$$

(B) Based on mean response values:

$$
\begin{aligned}
\operatorname{Maximize} \mathrm{F}_{1}= & \text { Maximize MRR } \\
= & 0.018953-0.36152 * \mathrm{X}_{1}+0.00314 * \mathrm{X}_{2} \\
& -0.00024 * \mathrm{X}_{3}+0.299 * \mathrm{X}_{1} * \mathrm{X}_{5} .
\end{aligned}
$$

Minimize $\mathrm{F}_{2}=$ Minimize $R a$

$$
\begin{aligned}
= & 2.32+172.77 * \mathrm{X}_{1}+0.504 * \mathrm{X}_{2} \\
& -0.569 * \mathrm{X}_{5}-162.54 * \mathrm{X}_{1} * \mathrm{X}_{5} .
\end{aligned}
$$

Minimize $\mathrm{F}_{3}=$ Minimize WER

$$
\begin{aligned}
= & 3.314-42.89 * \mathrm{X}_{1}-0.313 * \mathrm{X}_{2} \\
& +455 *\left(\mathrm{X}_{1}\right)^{2}+0.032 *\left(\mathrm{X}_{1}\right)^{2} \\
& -2.21 * \mathrm{X}_{1} * \mathrm{X}_{2} .
\end{aligned}
$$

Subject To:

$$
\begin{gathered}
0 \leq X_{1} \leq 0.05 ; 2 \leq X_{2} \leq 6 ; 50 \leq X_{3} \leq 70 ; 0.5 \leq X_{5} \leq 1 \\
X_{1}, X_{2}, X_{3}, X_{5} \geq 0 .
\end{gathered}
$$

The combined objective function gives similar equal weight for the three objectives $(\mathrm{C} 1=\mathrm{C} 2=\mathrm{C} 3=0.333333)$ as shown in Eq. (19).

$$
Z=-0.333 * \mathrm{~F}_{1}+0.333 * \mathrm{~F}_{2}+0.333 * \mathrm{~F}_{3} .
$$

Table 15 gives results of multi-objective based on $S / N$ ratio and mean values. Figure 11 gives the progress of optimization 
Table 16. Multi-objective solutions with different values of weighting factors (C1, C2, and $\mathrm{C} 3$ ) based on $S / N$ ratios.

\begin{tabular}{lcrr}
\hline & & $S / N$ ratio response values & \\
\cline { 2 - 4 } No. & Values of weighting factors $(\mathrm{C} 1, \mathrm{C} 2, \mathrm{C} 3)$ & $X^{*}$ & $F^{*}=[\mathrm{C} 1 \cdot \mathrm{F} 1 *, \mathrm{C} 2 \cdot \mathrm{F} 2 *, \mathrm{C} 3 \cdot \mathrm{F} 3 *]$ \\
\hline 1 & $\mathrm{C} 1=\mathrm{C} 2=\mathrm{C} 3=0.333333$ & $(0.042,6,50,0.99)$ & $(40.38,4.77,0.25)$ \\
2 & $\mathrm{C} 1=0.2, \mathrm{C} 2=0.3, \mathrm{C} 3=0.5$ & $(0.050,6,51.36,1)$ & $(06.90,4.34,0.01)$ \\
3 & $\mathrm{C} 1=0.3, \mathrm{C} 2=0.5, \mathrm{C} 3=0.2$ & $(0.022,6,50,0.99)$ & $(16.11,2.81,0.82)$ \\
4 & $\mathrm{C} 1=0.5, \mathrm{C} 2=0.2, \mathrm{C} 3=0.3$ & $(0.027,6,50,0.99)$ & $(09.91,5.69,0.40)$ \\
5 & $\mathrm{C} 1=0.3, \mathrm{C} 2=0.4, \mathrm{C} 3=0.3$ & $(0.037,6.00,50,1)$ & $(13.10,4.23,0.55)$ \\
6 & $\mathrm{C} 1=0.4, \mathrm{C} 2=0.3, \mathrm{C} 3=0.3$ & $(0.049,6.00,50,1)$ & $(10.22,4.34,0.04)$ \\
7 & $\mathrm{C} 1=0.3, \mathrm{C} 2=0.3, \mathrm{C} 3=0.4$ & $(0.045,5.99,50,1)$ & $(13.49,2.87,0.18)$ \\
8 & $\mathrm{C} 1=0.4, \mathrm{C} 2=0.2, \mathrm{C} 3=0.4$ & $(0.050,5.64,50,1)$ & $(06.97,5.63,0.04)$ \\
9 & $\mathrm{C} 1=0.2, \mathrm{C} 2=0.4, \mathrm{C} 3=0.4$ & $(0,6.00,50.00,0.5)$ & $(11.95,5.14,1.62)$ \\
\hline
\end{tabular}

Where $X^{*}$ denotes optimum values for selected control parameters. $F^{*}$ denotes optimum response value for each objective function. C1 denotes weighting factor for MRR objective function. C2 denotes weighting factor for $R a$ objective function. C3 denotes weighting factor for EWR objective function.

Table 17. Multi-objective solutions with different values of weighting factors $(\mathrm{C} 1, \mathrm{C} 2$, and $\mathrm{C} 3)$ based on mean values.

\begin{tabular}{lcrr}
\hline \multicolumn{2}{c}{ Mean response values } \\
\hline No. & Values of weighting factors $(\mathrm{C} 1, \mathrm{C} 2, \mathrm{C} 3)$ & $X^{*}$ & $F^{*}=[\mathrm{C} 1 \cdot \mathrm{F} 1 *, \mathrm{C} 2 \cdot \mathrm{F} 2 *, \mathrm{C} 3 \cdot \mathrm{F} 3 *]$ \\
\hline 1 & $\mathrm{C} 1=\mathrm{C} 2=\mathrm{C} 3=0.333333$ & $(0.042,2.02,50,1)$ & $(0.0035,1.06,0.543)$ \\
2 & $\mathrm{C} 1=0.2, \mathrm{C} 2=0.3, \mathrm{C} 3=0.5$ & $(0.045,2.00,50,1)$ & $(0.002,0.965,0.804)$ \\
3 & $\mathrm{C} 1=0.3, \mathrm{C} 2=0.5, \mathrm{C} 3=0.2$ & $(0.024,2.00,50,1)$ & $(0.003,1.502,0.388)$ \\
4 & $\mathrm{C} 1=0.5, \mathrm{C} 2=0.2, \mathrm{C} 3=0.3$ & $(0.045,2.00,50,1)$ & $(0.005,0.643,0.482)$ \\
5 & $\mathrm{C} 1=0.3, \mathrm{C} 2=0.4, \mathrm{C} 3=0.3$ & $(0.037,2.00,50,1)$ & $(0.003,1.255,0.506)$ \\
6 & $\mathrm{C} 1=0.4, \mathrm{C} 2=0.3, \mathrm{C} 3=0.3$ & $(0.040,2.00,50,1)$ & $(0.004,0.950,0.495)$ \\
7 & $\mathrm{C} 1=0.3, \mathrm{C} 2=0.3, \mathrm{C} 3=0.4$ & $(0.048,2.67,50,1)$ & $(0.003,0.962,0.646)$ \\
8 & $\mathrm{C} 1=0.4, \mathrm{C} 2=0.2, \mathrm{C} 3=0.4$ & $(0.041,2.00,50,1)$ & $(0.004,0.717,0.565)$ \\
9 & $\mathrm{C} 1=0.2, \mathrm{C} 2=0.4, \mathrm{C} 3=0.4$ & $(0.027,2.00,50,1)$ & $(0.002,1.271,0.656)$ \\
10 & $\mathrm{C} 1=0.4, \mathrm{C} 2=0.4, \mathrm{C} 3=0.2$ & $(0.004,1.214,0.374)$ \\
\hline
\end{tabular}

vs. iteration number (generation size) for $S / N$ ratio and mean values. Different weights are given to the optimization code and results are given in Table 16. In results based on $S / N$ ratio values, values of $\mathrm{X}_{2}, \mathrm{X}_{3}$, and $\mathrm{X}_{5}$ don't change in almost trials and their values are nearly to $6,50,1$ respectively, but $X_{1}$ is changed with different weighting factors. On the other hand, results based on mean are the same in $S / N$ ratio, but $\mathrm{X}_{2}$ is nearly to 2 respectively. Since results based on L27OA array are used, this means that $\mathrm{X}_{1}$ still confound parameter.

Optimization of mathematical models developed previously using Genetic Algorithms (GAs) is given. MATLAB code are developed for the single and multi-optimization models. As such, the loop is closed; experimental data is gathered, mathematical models are developed, validated and finally models are optimized. Now, optimum process settings are known to maximize individually material removal rate (MRR), minimize average surface roughness $(R a)$ and minimize Wear Electrode Ratio (EWR) respectively or as a combined multi-objective optimization problem with equal and different weights as given in Tables 15-17.

\section{Conclusions and future work}

In this paper, an L27OA (three-levels, five variables with interactions) is employed to plan experimentation of the
EDM process. This is equivalent to $3^{5}=243$ plus the interactions. The use of L27OA is equivalent to $27 / 243=1 / 9$ of experiments required. Any higher orthogonal array such as L81OA and L243OA could have been used [7]. Aluminum Carbon nanotubes composites are used for experimentation. Any material can be used instead; however the importance of the chosen composites is justified by the increasing applications. The models for material removal rate, wear electrode ratio and average surface roughness are specific for the chosen material and range of the control variables. Validation of RSM models indicates average percentage deviation in material removal rate, surface roughness and wear electrode ratio based on $S / N$ ratio values are $7.31 \%, 12.67 \%$, and $28.63 \%$ respectively. Based on mean values, the average percentage of deviation are $29.7 \%, 18.9 \%$, and $20.3 \%$ respectively. Based on standard deviations, the average percentage of deviation in material removal rate and electrode wear ratio are $38.9 \%$ and $30 \%$ respectively. Repeatability of results is an important issue in process modeling, analysis and optimization. Here, surface roughness is measured using two similar devices. Good repeatability is noticed. The accuracy of these models can be enhanced by increasing the number of trials over wider domains of process variables. More interactions can be included in model development. Other EDM process parameter such as: Pulse-on Time $\left(T_{\text {on }}\right)$, Pulse-off Time $\left(T_{\text {off }}\right)$, spark gap, and different electrode materials can be studied. 
In addition, several quality responses can be measured such as fatigue life.

Other two-level, three-level and mixed type orthogonal arrays can be used to study EDM process. Cost of carrying experimentation can be used as an objective besides already studied objectives. Other Nano-composite materials of interest can be employed besides Al-CNT composites. A comparative study can be produced based on statistical designs. The machine condition needs further elaboration in relation to process variables range. Noise related to the machine employed requires further quantification.

\section{References}

1. S. Singh, S. Maheshwari, P.C. Pandey, Some investigations into the electric discharge machining of hardened tool steel using different electrode materials, Journal of Materials Processing Technology 149 (2004) 272-277.

2. A. De Silva, J. Rankine, Electrical discharge machining of metal matrix composites, ISEM XI International Symposium for Electro Machining (1995) 75-84.
3. R. Karthikeyan, P.R. Lakshmi Narayanan, R.S. Naagarazan, Mathematical modelling for electric discharge machining of aluminium-silicon carbide particulate composites, Journal of Materials Processing Technology 87 (1999) 59-63.

4. S. Gopalakannan, T. Senthilvelan, Ranganathan, Modeling and optimization of EDM process parameters on machining of AL7075- $\mathrm{B}_{4} \mathrm{C}$ MMC using RSM, Procedia Engineering 38 (2012) 685-690.

5. S.S. Habib, Study of the parameters in electrical discharge machining through response surface methodology approach, Applied Mathematical Modeling 12 (2009) 4397-4407.

6. I. Puertas, C.J. Luis, L. Álvarez, Analysis of the influence of EDM parameters on surface quality, MRR and EW of WC-Co, Journal of Materials Processing Technology 153-154 (2004) 1026-1032.

7. P. Ross, Taguchi Techniques for Quality Engineering-Loss Function, Orthogonal Experiments, McGraw-Hill, Parameter and Tolerance Design, 1988.

8. Carnegie University, School of Computer Science web site. http://www.cs.cmu.edu/Groups/AI/html/faqs/ai/genetic/part2/faqdoc-2.html/[10February 2014].

Cite this article as: Hegab HA, Gadallah MH \& Esawi AK: Modeling and optimization of Electrical Discharge Machining (EDM) using statistical design. Manufacturing Rev. 2015, 2, 21. 